\title{
Mitigating the Growth, Biochemical Changes, Genotoxic and Pathological Effects of Copper Toxicity in Broiler Chickens by Supplementing Vitamins $C$ and $E$
}

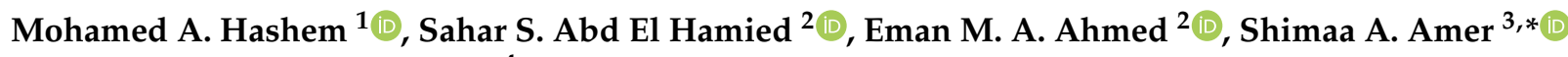 \\ and Mohamed E. El-Sharnouby ${ }^{4}$
}

check for updates

Citation: Hashem, M.A.; Abd El Hamied, S.S.; Ahmed, E.M.A.; Amer, S.A.; El-Sharnouby, M.E. Mitigating the Growth, Biochemical Changes, Genotoxic and Pathological Effects of Copper Toxicity in Broiler Chickens by Supplementing Vitamins $C$ and E. Animals 2021, 11, 1811. https:// doi.org/10.3390/ani11061811

Academic Editors: Anna Czech and Ewa Tomaszewska

Received: 22 April 2021

Accepted: 9 June 2021

Published: 17 June 2021

Publisher's Note: MDPI stays neutral with regard to jurisdictional claims in published maps and institutional affiliations.

Copyright: (c) 2021 by the authors. Licensee MDPI, Basel, Switzerland. This article is an open access article distributed under the terms and conditions of the Creative Commons Attribution (CC BY) license (https:// creativecommons.org/licenses/by/ $4.0 /)$.
1 Clinical Pathology Department, Faculty of Veterinary Medicine, Zagazig University, Zagazig 44511, Egypt; mhashem.vet@gmail.com

2 Clinical Pathology Department, Animal Health Institute, Zagazig Branch, Zagazig 44511, Egypt; sahar_elmasry91@yahoo.com (S.S.A.E.H.); emanalilogy@gmail.com (E.M.A.A.)

3 Department of Nutrition \& Clinical Nutrition, Faculty of Veterinary Medicine, Zagazig University, Zagazig 44511, Egypt

4 Department of Biotechnology, College of Science, Taif University, P.O. Box 11099, Taif 21944, Saudi Arabia; m.sharnouby@Tu.edu.sa

* Correspondence: shimaa.amer@zu.edu.eg

Simple Summary: Copper $(\mathrm{Cu})$ is a trace element necessary for biological utility; nevertheless, it can produce significant harmful impacts when existing in abundance. This study examined the efficiency of vitamin $\mathrm{C}$ and vitamin $\mathrm{E}$ in alleviating the biochemical, genotoxicity, and pathological alterations in the liver induced by copper sulfate $\left(\mathrm{CuSO}_{4}\right)$ toxicity in chickens. The broilers were fed on five experimental diets; basal diet with no additives or basal diets supplemented with $300 \mathrm{mg} \mathrm{CuSO} / \mathrm{kg}$, $\mathrm{CuSO}_{4}+250 \mathrm{mg}$ Vit. C/kg diet, $\mathrm{CuSO}_{4}+250 \mathrm{mg}$ Vit. E/kg diet, $\mathrm{CuSO}_{4}+250 \mathrm{mg}$ Vit. C/kg diet + $250 \mathrm{mg}$ Vit. E/ kg diet for six weeks. The obtained results suggested that addition of vitamin $\mathrm{C}$ and E, especially in combination, was beneficial for alleviating the harmful effects of $\mathrm{CuSO}_{4}$ toxicity on growth performance and liver histoarchitecture in broiler chickens.

Abstract: This experiment was carried out to explore the efficiency of an individual or combined doses of vitamin C (Vit. C) and vitamin E (Vit. E) in alleviating biochemical, genotoxicity, and pathological changes in the liver induced by copper sulfate $\left(\mathrm{CuSO}_{4}\right)$ toxicity in broiler chickens. Two hundred and fifty-one-day-old broiler chicks were haphazardly allotted into five groups (five replicates/group, ten chicks/replicate). The birds were fed five experimental diets; (1) basal diet with no additives (CON), (2) basal diets supplemented with $300 \mathrm{mg} \mathrm{CuSO} / 4 \mathrm{~kg} \operatorname{diet}\left(\mathrm{CuSO}_{4}\right)$, (3) basal diets supplemented with $300 \mathrm{mg} \mathrm{CuSO} / \mathrm{kg}$ diet $+250 \mathrm{mg}$ Vit. C / kg diet, (4) basal diets supplemented with $300 \mathrm{mg} \mathrm{CuSO}_{4} / \mathrm{kg}$ diet $+250 \mathrm{mg}$ Vit. E $/ \mathrm{kg}$ diet, (5) basal diets supplemented with $300 \mathrm{mg}$ $\mathrm{CuSO}_{4} / \mathrm{kg}$ diet $+250 \mathrm{mg}$ Vit. C $/ \mathrm{kg}$ diet $+250 \mathrm{mg}$ Vit. E $/ \mathrm{kg}$ diet for six weeks. The results displayed that $\mathrm{CuSO}_{4}$-intoxicated birds had significantly $(p<0.05)$ decreased bodyweight, weight gain, and feed intake with increased feed conversion ratio from the 2nd week till the 6th week compared with the CON. However, these changes were minimized by single or combined supplementation of vitamin C and E. The FCR was insignificantly different in birds-fed diets complemented with vitamin $C$ and $E$ singly or in combination from the 3rd week of age compared to the CON. Serum aminotransferases (ALT, AST) and alkaline phosphatase (ALP) were elevated in $\mathrm{CuSO}_{4}$-intoxicated birds $(p<0.05)$. Additionally, they showed a drop in serum total protein (TP), albumin, globulins, triglycerides (TG), total cholesterol (TC), low-density lipoprotein-cholesterol (LDL-C), very lowdensity lipoprotein-cholesterol (VLDL-C), and high-density lipoprotein-cholesterol (HDL-C) levels compared to the CON $(p<0.05)$. Concomitantly, histopathological and DNA changes were perceived in the liver of $\mathrm{CuSO}_{4}$-intoxicated birds. Co-supplementation of Vit. C and Vit. E single-handedly or combined with $\mathrm{CuSO}_{4}$-intoxicated chickens enhanced the performance traits and abovementioned changes, especially with those given combinations of vitamins. From the extant inquiry, it could be established that supplementation of vitamin $\mathrm{C}$ and $\mathrm{E}$ was beneficial for mitigating the harmful effects of $\mathrm{CuSO}_{4}$ toxicity on growth performance and liver histoarchitecture in broiler chickens. 
Keywords: copper toxicity; antioxidants; liver function tests; liver histoarchitecture; lipid profile

\section{Introduction}

The proper activities of iron metabolism-related metalloenzymes are maintained by copper $(\mathrm{Cu})$, a vital microelement involved in poultry diets [1]. Despite the need for unlike enzyme activities and metabolic processes, chronic overexposure to copper caused adverse effects [2]. This leads to cell death because of its ability to stimulate the production of Reactive Oxygen Species (ROS) [3]. Copper has a narrow optimum range between elemental and toxic concentrations [4]. Naturally, some types of soil contain $\mathrm{Cu}$ in toxic levels. In contrast, others may comprise high $\mathrm{Cu}$ levels through the human release of heavy metals into the environment through melting, mining, farming, industrial, and waste removal practices [5]. In poultry, the extreme type of $\mathrm{Cu}$ poisoning is the long-term ingestion of $\mathrm{Cu}$ compounds from different sources [6]. Copper metabolism, its release into the circulatory system or excretion through the bile, is controlled primarily by the liver [7]. It accumulates steadily in the liver during chronic $\mathrm{Cu}$ toxicity without causing any noticeable signs or symptoms. When the liver storage capacity is surpassed, it can lead to hepatocellular lesions and the $\mathrm{Cu}$ releases into the blood circulation causing jaundice, hemolysis, and renal disease [8]. The studies mentioned above have designated that excessive exposure to $\mathrm{Cu}$ can cause oxidative stress in the brain tissue of chickens [9], reduce the glutathione peroxidase and copper-zinc superoxide dismutase activities, and increase the contents of hydroxyl radical and malondialdehyde in the liver of ducklings [10]. A discrepancy between production of ROS and the ability of the body to detoxify these intermediate species is indicative of oxidative stress. Wang et al. [4] showed that $\mathrm{Cu}$ encourages oxidative damage in skeletal muscles of chickens through autophagy, apoptosis, and mitochondrial dynamics, thus expressing fears about poultry raising zones polluted with Cu. Moreover, Wang et al. [11] reported nephrotoxicity in Cu-intoxicated chickens due to oxidative damage of the kidney. Although $\mathrm{Cu}$ supplementation of up to $200 \mathrm{ppm}$ is necessary to promote growth, excessive amounts of dietary $\mathrm{Cu}$ reduce growth. It reduces the digestibility and absorption of copper in poultry, which leads to increased excretion in the faeces and environmental pollution. [12].

Few reports have displayed that supplementation of antioxidants such as vitamin C vitamin E, polyphenols, alpha-lipoic acid, beta-carotene, and zinc has a protective impact against the toxicity of $\mathrm{Cu}[13,14]$. However, only restricted studies have been achieved on the effects of vitamin $C$ and E single-handedly or incorporating on growth performance, biochemical markers, DNA damage, or pathological findings in broilers fed excess dietary $\mathrm{Cu}$. Consequently, the ambition of the existent inquest was to assess the effects of $\mathrm{Cu}$ intoxication on these parameters and then appraise the protecting impact of vitamins $\mathrm{C}$ and $\mathrm{E}$ against excess dietary supplementation with $\mathrm{Cu}$, individually or in combination. Therefore, this experiment aimed to assess the mitigating effects of single or combined addition of vitamin $\mathrm{C}$ and $\mathrm{E}$ on the harmful impacts of $\mathrm{Cu}$ toxicity in broiler chickens.

\section{Material and Methods}

\subsection{Experimental Birds, Diet, and Protocol}

This study was conducted in a poultry research unit in the faculty of veterinary medicine, Zagazig University, Egypt. The ethics of the experimental protocol were approved by the Institutional Animal Care and Use Committee of Zagazig University, Egypt (ZU-IACUC /2020). All animal experiments were performed following the recommendations described in "The Guide for the Care and Use of Laboratory Animals in scientific investigations."

Two hundred and fifty-one-day-old commercial broiler chickens (COBB-500) were attained from Al-Kahira Poultry Company, 10th of Ramadan City, Sharkia Governorate, Egypt. The experiment lasted for 42 days with good ventilation. Birds were raised in 
an open, well-ventilated house with sawdust. Room temperature was controlled and thermostatically regulated by two heaters. Room temperature during the first week was set at $34{ }^{\circ} \mathrm{C}$ and gradually reduced by $3{ }^{\circ} \mathrm{C}$ every week until it reached $24{ }^{\circ} \mathrm{C}$. The light program for the first week was 24 hours a day and then changed to $16 \mathrm{~h}$ of light and 8 hours of dark over 7 to 42 days.

Freshwater and feed were offered for ad libitum consumption throughout the experiment. The chicks were given a starter diet from one day until the 10th day of age, a grower diet (11th-22nd day), followed by a finisher diet up to 42-days of age. Ingredients and chemical composition of diets were formulated as designated by the COBB-500 broiler manual guide [15] (Table 1). All birds were vaccinated at 7 and 14 days old against Newcastle disease and 11 and 22 days old for Gumboro disease [16].

Table 1. Proximate and chemical composition of the basal diets (\%).

\begin{tabular}{|c|c|c|c|}
\hline Ingredients & $\begin{array}{l}\text { Starter Stage } \\
\text { (1-10 Day) }\end{array}$ & $\begin{array}{l}\text { Grower Stage } \\
\text { (11-22 Day) }\end{array}$ & $\begin{array}{l}\text { Finisher Stage } \\
\text { (23-42 Day) }\end{array}$ \\
\hline Soybean meal, $48 \%$ & 34.66 & 28.2 & 25 \\
\hline Yellow corn & 58 & 62 & 63.5 \\
\hline Corn gluten, $60 \%$ & 1.5 & 3 & 3 \\
\hline Wheat bran & - & 1.1 & 1.8 \\
\hline Soy oil & 2 & 2 & 3.26 \\
\hline Calcium dibasic phosphate & 1.8 & 1.7 & 1.5 \\
\hline Calcium carbonate & 1 & 1 & 1 \\
\hline Premix * & 0.3 & 0.3 & 0.3 \\
\hline Lysine, $\mathrm{Hcl}, 78 \%$ & 0.16 & 0.16 & 0.13 \\
\hline Common salt & 0.3 & 0.3 & 0.3 \\
\hline DL-Methionine, $98 \%$ & 0.18 & 0.14 & 0.11 \\
\hline Anti-mycotoxin & 0.1 & 0.1 & 0.1 \\
\hline \multicolumn{4}{|c|}{ Chemical composition (\%) } \\
\hline $\mathrm{ME}, \mathrm{Kcal} / \mathrm{Kg}$ & 3047.51 & 3090.11 & 3178.56 \\
\hline Crude protein & 22.16 & 20.42 & 19.09 \\
\hline Crude fiber & 2.63 & 2.64 & 2.65 \\
\hline Fat & 4.51 & 4.63 & 5.89 \\
\hline Calcium & 0.97 & 0.94 & 0.88 \\
\hline Available P & 0.48 & 0.45 & 0.41 \\
\hline Methionine & 0.55 & 0.48 & 0.46 \\
\hline Lysine & 1.37 & 1.20 & 1.09 \\
\hline
\end{tabular}

* Premix per kg of diet: vitamin A, $1500 \mathrm{IU}$; vitamin D3, $200 \mathrm{IU}$; vitamin E, $10 \mathrm{mg}$; vitamin K3, $0.5 \mathrm{mg}$; thiamine, $1.8 \mathrm{mg}$; riboflavin, $3.6 \mathrm{mg}$; pantothenic cid, $10 \mathrm{mg}$; folic acid, $0.55 \mathrm{mg}$; pyridoxine, $3.5 \mathrm{mg}$; niacin, $35 \mathrm{mg}$; cobalamin, $0.01 \mathrm{mg}$; biotin, $0.15 \mathrm{mg}$; $\mathrm{Fe}, 80 \mathrm{mg}$; $\mathrm{Cu}, 8 \mathrm{mg}$; $\mathrm{Mn}$, $60 \mathrm{mg}$; Zn, 40 mg; I, 0.35 mg; Se, 0.15 mg. ME: metabolizable energy; P: phosphorus.

The chicks were haphazardly allotted into five experimental groups (five replicates/ group, 10 chicks/replicates). The birds were fed on five experimental diets; (1) basal diet with no additives (CON), (2) basal diets supplemented with $300 \mathrm{mg} \mathrm{CuSO} / \mathrm{kg}$ diet $\left(\mathrm{CuSO}_{4}\right)$, (3) basal diets supplemented with $300 \mathrm{mg} \mathrm{CuSO} 4 / \mathrm{kg}$ diet $+250 \mathrm{mg}$ Vit. C $/ \mathrm{kg}$ diet, (4) basal diets supplemented with $300 \mathrm{mg} \mathrm{CuSO} / \mathrm{kg}$ diet $+250 \mathrm{mg}$ Vit. E / kg diet, (5) basal diets supplemented with $300 \mathrm{mg} \mathrm{CuSO} / 4 \mathrm{~kg}$ diet $+250 \mathrm{mg}$ Vit. C $/ \mathrm{kg}$ diet $+250 \mathrm{mg}$ Vit. E/ $\mathrm{kg}$ diet for six weeks. Copper sulfate $\left(\mathrm{CuSO}_{4} \cdot 5 \mathrm{H}_{2} \mathrm{O}\right.$, El-Gomhoria industry, Zagazig, Egypt), vitamin C (ROVIMIX ${ }^{\circledR}$ STAY-C ${ }^{\circledR} 35$, DSM, Heerlen, The Netherlands), and vitamin E ( $\alpha$ tocopherol acetate, Pharco Pharmaceutical Industries, Zagazig, Egypt). The toxic dose of $\mathrm{Cu}$ used in this inquest was dogged according to Cinar et al. [17], while the vitamins $\mathrm{C}$ and $\mathrm{E}$ doses were used after Sahin et al. [18].

\subsection{Growth Performance}

The average initial body weight (BW) was recorded at the beginning of the experiment. The BW was then determined every week, and body weight gain (BWG) was determined [19]. The difference between the weight of the provided feed and the feed that 
remained was used to calculate feed intake (FI) per replicate. Then, the feed conversion ratio (FCR) was calculated. FCR = amount of consumed feed (g)/BWG (g).

\subsection{Sampling}

Samples of blood were collected from the wing vein of 10 randomly selected birds in each group at the termination of $3 \mathrm{rd}$ and 6th weeks post-supplementations and centrifuged (3000 rpm for $15 \mathrm{~min}$ ) immediately for separation of serum, which is stored at $-20^{\circ} \mathrm{C}$ in deep freeze until biochemical analysis [20]. The chicks were euthanized using cervical dislocation, according to the American Veterinary Medical Association (Schaumburg, IL, USA) guidelines [21], and two portions of liver tissues were separated and blotted dry. The first part was put in ice-cold PBS (phosphate buffer saline) for comet assay determination, and the 2nd part was fixed in ten percent formalin for histopathological inspection.

\subsection{Blood Biochemical Studies}

The serum activities of alanine aminotransferase (ALT) and aspartate aminotransferase (AST) were determined according to the method of Reitman and Frankel [22]. The serum alkaline phosphatase activity was measured according to the modified method of Moss [23].

The serum total protein levels were estimated according to Grant [24]. The serum albumin level was evaluated according to Doumas et al. [25]. According to Doumas and Biggs [26], the serum globulins levels were calculated mathematically by subtracting albumin values from total protein values.

The total serum lipids, total cholesterol, triglyceride, and high-density lipoprotein (HDL-c) were estimated according to the methods of Zöllner and Kirsch [27], Roeschlau et al. [28], McGowan et al. [29], and Young [30], respectively. Low-density lipoprotein (LDLc) and very-low-density lipoprotein cholesterol (VLDL-C) were calculated mathematically according to the following relationship described by Friedewald et al. [31].

\subsection{Detection of DNA Damage}

The liver DNA damage was measured using a single-cell gel electrophoresis technique (also known as comet assay) as previously defined by Singh et al. [32]. Comet assay is a quick, accurate, and simple method for detecting DNA damage. In this method, $0.5 \mathrm{~g}$ of crushed samples were transferred to $1 \mathrm{~mL}$ ice-cold PBS. This suspension was stirred for $5 \mathrm{~min}$ and filtered. The cell suspension $(100 \mu \mathrm{L})$ was mixed with $600 \mu \mathrm{L}$ of low melting agarose $(0.8 \%$ in PBS). A $100 \mu \mathrm{L}$ of this mixture was spread on precoated slides. The coated slides were immersed in lysis buffer $(0.045 \mathrm{~mol} / \mathrm{L}$ Tris/Borate/EDTA (TBE), $\mathrm{pH} 8.4$, containing $2.5 \%$ sodium dodecyl sulfate (SDS)) for $15 \mathrm{~min}$. The electrophoresis conditions were $2 \mathrm{~V} / \mathrm{cm}$ for $2 \mathrm{~min}$ and $100 \mathrm{~mA}$. The slides were then washed 3 times, for $5 \mathrm{~min}$ each, with neutralization buffer $(0.4 \mathrm{Mol} / \mathrm{L}$ Tris ( $\mathrm{pH} 7.5))$. Finally, the slides were stained with $50 \mathrm{AL}$ of ethidium bromide $(2 \mathrm{mg} / \mathrm{mL})$ and covered with a coverslip.

The DNA fragment migration patterns of 100 cells at 400 magnifications with the Optika Axioscope fluorescence microscope were calculated for each dose level. The length of DNA migration (tail length) on PX was calculated for each cell from the center of the nucleus to the termination of the tail. By calculating the total intensity (fluorescence) in the cells, which was taken as $100 \%$, the DNA \% in the tail was determined, deciding what percentage of this total intensity corresponded to the intensity only measured in the tail. The tail moment was expressed in arbitrary units. Although any image analysis device may be sufficient for SCGE data quantification, Comet 5 image analysis software developed by Kinetic Imaging Ltd. (Liverpool, UK) linked to a CCD camera has been used to determine the degree of quantitative and qualitative DNA damage in the cells by measuring the length of DNA migration and the \% of migrated DNA. Finally, the program calculated the tail moment. Generally, 100 randomly selected cells are analyzed per sample. 


\subsection{Histopathological Investigations}

Samples were taken from the liver of euthanized chicks by manual cervical dislocation and fixed in formalin of $10 \%$. The samples preserved with formalin are dehydrated and embedded in paraffin. Five-micron-thick paraffin slices were set and stained with hematoxylin and eosin (H\&E) and inspected microscopically [33].

\subsection{Statistical Analysis}

Data were analyzed with a one-way analysis of variance (ANOVA) using the GLM procedure in SPSS (SPSS Inc., Chicago, IL, USA) after Shapiro-Wilk's test was used to verify the normality and Levene's test was used to verify homogeneity of variance components between experimental treatments. Duncan's test was used to compare the differences between the means at $5 \%$ probability [34]. Variation in the data was expressed as mean \pm $\mathrm{SD}$, and the significance level was set at $p<0.05$.

\section{Results}

\subsection{Clinical Signs and Body Performance}

No clinical signs or mortality were found in all supplemented birds (single or combined Vit. $\mathrm{C}$ and Vit. E addition) during the experimental period. The $\mathrm{CuSO}_{4}$-intoxicated group showed mild diarrhea (few cases), decreased appetite, and pale comb.

As presented in Table 2, the BW, BWG, and feed intake of broilers were significantly declined in all groups from the $2^{\text {nd }}$ week till the termination of the experiment (6th week) compared to the CON group $(p<0.05)$. However, these changes were minimized in birds supplemented with vitamins $\mathrm{C}$ and $\mathrm{E}$ compared with $\mathrm{CuSO}_{4}$-intoxicated group. The FCR was significantly higher in $\mathrm{CuSO}_{4}$-intoxicated broilers at the 2nd to 6th week of age compared to the control group $(p<0.05)$. Comparatively, with the CON group, the FCR was insignificantly different in birds fed diets supplemented with vitamin $C$, and E singly or in combination from the 3 rd week of age and went back to near average control values at the 6 th week $(p<0.05)$.

Table 2. Effect of single or combined supplementation of vitamin $\mathrm{C}$ and $\mathrm{E}$ on the growth performance of $\mathrm{CuSO}_{4}$-intoxicated broiler chickens (Mean $\pm \mathrm{SD}$ ).

\begin{tabular}{|c|c|c|c|c|c|c|c|}
\hline Parameters & Weeks & $\mathrm{CON}$ & $\mathrm{CuSO}_{4}$ & $\mathrm{CuSO}_{4}+$ Vit. $\mathrm{C}$ & $\mathrm{CuSO}_{4}+$ Vit. $\mathrm{E}$ & $\mathrm{CuSO}_{4}+$ Vit. $\mathrm{C}+$ Vit. $\mathrm{E}$ & $p$-Value \\
\hline Int. BW & & $43.8 \pm 4.15$ & $43.8 \pm 4.14$ & $44.0 \pm 2.23$ & $43.8 \pm 2.77$ & $43.4 \pm 2.30$ & 0.241 \\
\hline \multirow{6}{*}{ BW (g/bird) } & 1st week & $159.0 \pm 4.18$ & $152.2 \pm 6.83$ & $153.0 \pm 5.70$ & $154.0 \pm 5.47$ & $156.0 \pm 4.18$ & 0.120 \\
\hline & 2nd week & $430 \pm 16.95^{\mathrm{a}}$ & $377 \pm 20.73^{c}$ & $389 \pm 7.41^{c}$ & $399.4 \pm 11.33^{b c}$ & $422 \pm 12.04^{b}$ & 0.001 \\
\hline & 3rd week & $847 \pm 24.64^{a}$ & $712 \pm 23.87^{d}$ & $762 \pm 09.08^{c}$ & $783 \pm 09.08^{c}$ & $814 \pm 21.03^{b}$ & 0.001 \\
\hline & 4 th week & $1281 \pm 32.09^{a}$ & $1060 \pm 39.21^{\mathrm{d}}$ & $1149 \pm 27.70^{c}$ & $1178 \pm 16.43^{c}$ & $1221 \pm 28.15^{b}$ & 0.009 \\
\hline & 5 th week & $1818 \pm 44.24^{\mathrm{a}}$ & $1500 \pm 18.02^{e}$ & $1614 \pm 35.07^{\mathrm{d}}$ & $1663 \pm 25.64^{c}$ & $1716 \pm 42.48^{b}$ & 0.008 \\
\hline & 6 th week & $2430 \pm 63.54^{a}$ & $2000 \pm 25.49^{d}$ & $2136 \pm 42.92^{c}$ & $2198 \pm 44.38^{c}$ & $2271 \pm 68.32^{b}$ & 0.001 \\
\hline \multirow{6}{*}{$\begin{array}{l}\text { BWG } \\
\text { (g/bird) }\end{array}$} & 1st week & $115.2 \pm 5.00$ & $108.4 \pm 7.56$ & $109.0 \pm 6.51$ & $110.2 \pm 3.27$ & $112.6 \pm 4.87$ & 0.542 \\
\hline & 2nd week & $271 \pm 16.35^{a}$ & $224.8 \pm 37.92^{c}$ & $236 \pm 8.94^{b c}$ & $250 \pm 15.00^{a b}$ & $266 \pm 12.44^{b}$ & 0.000 \\
\hline & 3rd week & $417 \pm 22.09^{a}$ & $335 \pm 21.21^{c}$ & $373 \pm 6.70^{b}$ & $383.6 \pm 15.56^{b}$ & $392 \pm 12.54^{b}$ & 0.000 \\
\hline & 4th week & $434 \pm 15.57^{\mathrm{a}}$ & $348 \pm 30.53^{c}$ & $387 \pm 30.12^{b}$ & $395 \pm 22.52^{b}$ & $407 \pm 26.12^{a b}$ & 0.001 \\
\hline & 5th week & $537 \pm 33.27^{\mathrm{a}}$ & $440 \pm 27.15^{c}$ & $465 \pm 21.50^{b c}$ & $485 \pm 20.30^{b}$ & $495 \pm 16.95^{b}$ & 0.001 \\
\hline & 6th week & $612 \pm 23.87^{a}$ & $500 \pm 26.45^{c}$ & $522 \pm 23.623^{b c}$ & $535 \pm 26.45^{b c}$ & $555 \pm 32.78^{b}$ & 0.000 \\
\hline \multirow{6}{*}{$\begin{array}{l}\text { Feed intake } \\
\text { (g/bird) }\end{array}$} & 1st week & $144.5 \pm 6.15$ & $139.85 \pm 7.25$ & $140 \pm 10.12$ & $141 \pm 9.20$ & $142.4 \pm 5.15$ & 0.270 \\
\hline & 2nd week & $370 \pm 20.15$ & $325 \pm 24.26$ & $333 \pm 15.14$ & $348 \pm 17.24$ & $365 \pm 35.10$ & 0.752 \\
\hline & 3rd week & $583 \pm 35.00^{\mathrm{a}}$ & $525 \pm 26.14^{c}$ & $537 \pm 19.15^{b}$ & $548 \pm 36.09^{b}$ & $557 \pm 24.10^{a b}$ & 0.000 \\
\hline & 4 th week & $700 \pm 27.12^{a}$ & $625 \pm 15.00^{c}$ & $635 \pm 20.8^{b}$ & $650 \pm 27.95^{b}$ & $660 \pm 37.00^{a b}$ & 0.000 \\
\hline & 5 th week & $900 \pm 33.14^{\mathrm{a}}$ & $810 \pm 31.13^{c}$ & $825 \pm 16.9^{b}$ & $845 \pm 32.09^{b}$ & $855 \pm 28.4^{b}$ & 0.009 \\
\hline & 6th week & $1070 \pm 55.12^{a}$ & $950 \pm 34.24^{c}$ & $965 \pm 29.9^{b}$ & $977 \pm 16.7^{\mathrm{b}}$ & $999 \pm 45.74^{a b}$ & 0.001 \\
\hline \multirow{6}{*}{ FCR } & 1st week & $1.25 \pm 0.05$ & $1.29 \pm 0.09$ & $1.28 \pm 0.07$ & $1.27 \pm 0.03$ & $1.26 \pm 0.05$ & 0.483 \\
\hline & 2nd week & $1.36 \pm 0.08$ & $1.45 \pm 0.12$ & $1.41 \pm 0.05$ & $1.39 \pm 0.08$ & $1.39 \pm 0.06$ & 0.335 \\
\hline & 3rd week & $1.40 \pm 0.06^{b}$ & $1.57 \pm 0.06^{\mathrm{a}}$ & $1.44 \pm 0.03^{b}$ & $1.43 \pm 0.05^{\mathrm{b}}$ & $1.42 \pm 0.04^{\mathrm{b}}$ & 0.000 \\
\hline & 4th week & $1.61 \pm 0.05^{b}$ & $1.79 \pm 0.17^{\mathrm{a}}$ & $1.65 \pm 0.13^{\mathrm{ab}}$ & $1.64 \pm 0.09^{a b}$ & $1.62 \pm 0.13^{\mathrm{ab}}$ & 0.007 \\
\hline & 5 th week & $1.67 \pm 0.10^{b}$ & $1.83 \pm 0.08^{a}$ & $1.77 \pm 0.08^{a b}$ & $1.74 \pm 0.07^{\mathrm{ab}}$ & $1.71 \pm 0.06^{\mathrm{ab}}$ & 0.000 \\
\hline & 6th week & $1.74 \pm 0.06^{b}$ & $1.90 \pm 0.10^{\mathrm{a}}$ & $1.84 \pm 0.08^{a b}$ & $1.82 \pm 0.09 \mathrm{ab}$ & $1.80 \pm 0.08^{\mathrm{ab}}$ & 0.000 \\
\hline
\end{tabular}

a, b, c, d Means carrying different superscripts are significantly different at $p<0.05$. BW: body weight, BWG: body weight gain, FCR: feed conversion ratio. 


\subsection{Serum Levels of Liver Biomarkers}

As shown in Tables 3-6, $\mathrm{CuSO}_{4}$ induced hepatotoxicity as reflected statistically $(p<0.05)$ by increased serum activities of ALT, AST, and ALP, whereas serum TP, albumin, globulins, TG, TC, LDL-C, VLDL-C, and HDL-C levels were reduced at 3rd and 6th week compared to CON $(p \leq 0.05)$. The decrease in serum albumin and HDL-C was only in the 6th week period.

Table 3. Effect of single or combined supplementation of vitamin $C$ and $E$ on broiler chickens' liver enzyme activities and protein profile at the end of the 3rd week (Mean $\pm \mathrm{SD}, n=5$ ).

\begin{tabular}{|c|c|c|c|c|c|c|}
\hline Parameters & CON & $\mathrm{CuSO}_{4}$ & $\mathrm{CuSO}_{4}+$ Vit. C & $\mathrm{CuSO}_{4}+$ Vit. E & $\mathrm{CuSO}_{4}+$ Vit. $\mathrm{C}+$ Vit. E & $p$-Value \\
\hline ALT (U/L) & $9.30 \pm 0.99^{c}$ & $21.60 \pm 6.14^{a}$ & $16.60 \pm 4.41^{b}$ & $15.60 \pm 4.41^{\mathrm{b}}$ & $13.10 \pm 3.29 b c$ & 0.001 \\
\hline AST (U/L) & $150.5 \pm 10.9^{d}$ & $193.7 \pm 9.2^{\mathrm{a}}$ & $177.9 \pm 5.6^{\mathrm{b}}$ & $171.8 \pm 7.4^{\mathrm{bc}}$ & $162.6 \pm 13.9^{\mathrm{cd}}$ & 0.001 \\
\hline $\operatorname{ALP}(\mathrm{U} / \mathrm{L})$ & $620 \pm 71.2^{c}$ & $727 \pm 58.3^{a}$ & $711 \pm 99.2^{\mathrm{a}}$ & $702 \pm 95.1^{\mathrm{a}}$ & $689 \pm 57.5^{b}$ & 0.001 \\
\hline $\mathrm{TP}(\mathrm{g} / \mathrm{dL})$ & $3.69 \pm 0.20^{a}$ & $3.33 \pm 0.18^{b}$ & $3.52 \pm 0.07^{b}$ & $3.65 \pm 0.12^{\mathrm{a}}$ & $3.67 \pm 0.32^{\mathrm{a}}$ & 0.000 \\
\hline Albumin (g/dL) & $1.99 \pm 0.13$ & $1.83 \pm 0.15$ & $1.84 \pm 0.15$ & $1.94 \pm 0.16$ & $1.95 \pm 0.15$ & 0.453 \\
\hline Globulins (g/dL) & $1.70 \pm 0.08^{a}$ & $1.50 \pm 0.09^{b}$ & $1.68 \pm 0.12^{\mathrm{a}}$ & $1.71 \pm 0.19^{a}$ & $1.72 \pm 0.13^{a}$ & 0.000 \\
\hline
\end{tabular}

a,b,c,d Means carrying different superscripts are significantly different at $p<0.05$. ALT: alanine aminotransferase, AST: aspartate aminotransferase, ALP: alkaline phosphatase, TP: total proteins.

Table 4. Effect of single or combined supplementation of vitamin $C$ and $E$ on broiler chickens' liver enzyme activities and protein profile at the end of the 6 th week (Mean $\pm \mathrm{SD}, n=5$ ).

\begin{tabular}{|c|c|c|c|c|c|c|}
\hline Parameters & $\mathrm{CON}$ & $\mathrm{CuSO}_{4}$ & $\mathrm{CuSO}_{4}+$ Vit. $\mathrm{C}$ & $\mathrm{CuSO}_{4}+$ Vit. $\mathrm{E}$ & $\mathrm{CuSO}_{4}+$ Vit. $\mathrm{C}+$ Vit. $\mathrm{E}$ & $p$-Value \\
\hline ALT (U/L) & $11.56 \pm 4.86^{c}$ & $24.42 \pm 5.00^{a}$ & $18.42 \pm 3.35^{\mathrm{b}}$ & $16.87 \pm 3.72^{b}$ & $15.25 \pm 3.12^{b c}$ & 0.001 \\
\hline AST (U/L) & $160.5 \pm 9.1^{\mathrm{d}}$ & $195.7 \pm 7.8^{a}$ & $182.3 \pm 5.5^{b}$ & $177.8 \pm 5.4^{b c}$ & $169.6 \pm 7.6^{\mathrm{cd}}$ & 0.001 \\
\hline $\operatorname{ALP}(\mathrm{U} / \mathrm{L})$ & $580 \pm 31.1^{b}$ & $660.0 \pm 54^{a}$ & $628 \pm 44^{a b}$ & $616 \pm 55^{\mathrm{ab}}$ & $578 \pm 30^{\mathrm{b}}$ & 0.000 \\
\hline $\mathrm{TP}(\mathrm{g} / \mathrm{dL})$ & $4.33 \pm 0.42^{\mathrm{a}}$ & $3.01 \pm 0.18^{b}$ & $4.15 \pm 0.36^{\mathrm{a}}$ & $4.17 \pm 0.40^{\mathrm{a}}$ & $4.30 \pm 0.33^{a}$ & 0.000 \\
\hline Albumin (g/dL) & $2.48 \pm 0.13^{\mathrm{a}}$ & $2.01 \pm 0.24^{b}$ & $2.27 \pm 0.19^{\mathrm{ab}}$ & $2.28 \pm 0.18^{\mathrm{ab}}$ & $2.30 \pm 0.20^{\mathrm{a}}$ & 0.011 \\
\hline Globulins (g/dL) & $1.85 \pm 0.69^{a}$ & $0.9 \pm 0.18^{b}$ & $1.88 \pm 0.25^{\mathrm{a}}$ & $1.89 \pm 0.24^{\mathrm{a}}$ & $2.00 \pm 0.32^{\mathrm{a}}$ & 0.000 \\
\hline
\end{tabular}

a,b,c,d Means carrying different superscripts are significantly different at $p<0.05$. ALT: alanine aminotransferase, AST: aspartate aminotransferase, ALP: alkaline phosphatase, TP: total proteins.

Table 5. Effect of single or combined supplementation of vitamin $\mathrm{C}$ and $\mathrm{E}$ on the lipid profile of broiler chickens at the end of the 3rd week (Mean $\pm \mathrm{SD}, n=5$ ).

\begin{tabular}{|c|c|c|c|c|c|c|}
\hline Parameters & $\mathrm{CON}$ & $\mathrm{CuSO}_{4}$ & $\mathrm{CuSO}_{4}+$ Vit. $\mathrm{C}$ & $\mathrm{CuSO}_{4}+$ Vit. $\mathrm{E}$ & $\mathrm{CuSO}_{4}+$ Vit. $\mathrm{C}+$ Vit. $\mathrm{E}$ & $p$-Value \\
\hline $\mathrm{TG}(\mathrm{mg} / \mathrm{dL})$ & $65.03 \pm 4.74^{\mathrm{a}}$ & $48.14 \pm 7.33^{c}$ & $50.90 \pm 5.57^{b c}$ & $53.64 \pm 3.49 b c$ & $60.12 \pm 5.91^{a b}$ & 0.000 \\
\hline $\mathrm{TC}(\mathrm{mg} / \mathrm{dL})$ & $155.82 \pm 2.94^{\mathrm{a}}$ & $126.79 \pm 11.00^{\mathrm{c}}$ & $130.48 \pm 6.75^{c}$ & $138.92 \pm 5.51^{b c}$ & $148.48 \pm 5.78^{a b}$ & 0.000 \\
\hline $\mathrm{LDL}-\mathrm{C}(\mathrm{mg} / \mathrm{dL})$ & $89.52 \pm 3.19^{a}$ & $70.65 \pm 7.74^{c}$ & $72.86 \pm 5.53^{c}$ & $78.56 \pm 1.95^{b c}$ & $84.66 \pm 3.94^{\mathrm{ab}}$ & 0.001 \\
\hline VLDL-C (mg/dL) & $13.00 \pm 0.98^{a}$ & $9.62 \pm 1.46^{c}$ & $10.17 \pm 1.11^{b c}$ & $10.72 \pm 0.69 b c$ & $12.02 \pm 1.18^{a b}$ & 0.000 \\
\hline HDL-C (mg/dL) & $53.29 \pm 3.49$ & $46.51 \pm 4.79$ & $47.43 \pm 2.60$ & $49.78 \pm 5.73$ & $52.12 \pm 7.23$ & 0.701 \\
\hline
\end{tabular}

a, b, c, d Means carrying different superscripts are significantly different at $p<0.05$. TG: triglycerides, TC: total cholesterol, LDL-C: low-density lipoprotein-cholesterol, VLDL-C: very low-density lipoprotein-cholesterol, HLDL-C: high-density lipoprotein-cholesterol.

Table 6. Effect of single or combined supplementation of vitamin $\mathrm{C}$ and $\mathrm{E}$ on the lipid profile of broiler chickens at the end of the 6th week (Mean $\pm \mathrm{SD}, n=5$ ).

\begin{tabular}{|c|c|c|c|c|c|c|}
\hline Parameters & CON & $\mathrm{CuSO}_{4}$ & $\mathrm{CuSO}_{4}+$ Vit. C & $\mathrm{CuSO}_{4}+$ Vit. E & $\mathrm{CuSO}_{4}+$ Vit. C + Vit. E & $p$-Value \\
\hline TG (mg/dL) & $67.96 \pm 2.32^{\mathrm{a}}$ & $50.58 \pm 5.42^{c}$ & $57.34 \pm 1.85^{b c}$ & $58.23 \pm 3.02^{b c}$ & $62.43 \pm 6.19^{a b}$ & 0.000 \\
\hline $\mathrm{TC}(\mathrm{mg} / \mathrm{dL})$ & $166.68 \pm 7.77^{a}$ & $130.86 \pm 4.15^{b}$ & $135.95 \pm 4.51^{b}$ & $141.36 \pm 7.65^{b}$ & $157.40 \pm 5.92^{\mathrm{a}}$ & 0.000 \\
\hline LDL-C (mg/dL) & $98.75 \pm 6.50^{\mathrm{a}}$ & $74.52 \pm 5.36^{c}$ & $79.38 \pm 4.59^{c}$ & $81.88 \pm 4.50^{b c}$ & $91.51 \pm 7.34^{\mathrm{ab}}$ & 0.000 \\
\hline VLDL-C (mg/dL) & $13.58 \pm 0.46^{\mathrm{a}}$ & $10.11 \pm 1.08^{c}$ & $11.46 \pm 0.36^{b c}$ & $11.64 \pm 0.60^{b c}$ & $12.48 \pm 1.23^{\mathrm{ab}}$ & 0.007 \\
\hline HDL-C (mg/dL) & $54.33 \pm 1.91^{\mathrm{ab}}$ & $46.22 \pm 3.1^{\mathrm{b}}$ & $47.95 \pm 4.07^{b}$ & $50.16 \pm 8.55^{b c}$ & $53.41 \pm 4.67^{\mathrm{ab}}$ & 0.000 \\
\hline
\end{tabular}

a, b, c Means carrying different superscripts are significantly different at $p<0.05$. TG: triglycerides, TC: total cholesterol, LDL-C: low-density lipoprotein-cholesterol, VLDL-C: very low-density lipoprotein-cholesterol, HLDL-C: high-density lipoprotein-cholesterol.

On the other hand, co-supplementation of copper with Vit. C and Vit. E significantly lowered the serum AST, ALT, and ALP and increased serum TP, albumin, globulins, TG, TC, LDL-C, VLDL-C, and HDL-C levels in the $\mathrm{CuSO}_{4}+$ Vit. $\mathrm{C}$ and $\mathrm{CuSO}_{4}+$ Vit. E groups 
compared with $\mathrm{CuSO}_{4}$-induced hepatotoxicity group. However, co-administration of $\mathrm{CuSO}_{4}+$ Vit. C + Vit. E restored liver biomarkers' changes near-normal control values.

\subsection{DNA Damage}

The data in Tables 7 and 8 and Figure 1 revealed that $\mathrm{CuSO}_{4}$ intoxication significantly elevated the comet \%, \%DNA in the tail, tail moment, olive tail moment, and tail length at the end of the 3rd and 6th week parallel to $\mathrm{CON}(p<0.05)$. On the contrary, coadministration of $\mathrm{CuSO}_{4}+$ Vit. $\mathrm{C}, \mathrm{CuSO}_{4}+$ Vit. E, or their combination $\left(\mathrm{CuSO}_{4}+\right.$ Vit. C + Vit. E) to birds ensued in an enhancement in the results of comet assay performance, showing a substantial decrease in previous parameters relative to the $\mathrm{CuSO}_{4}$-intoxicated group but did not return to values of standard control. It was evident that the vitamin combination led to a significant decrease in comparison to the $\mathrm{CuSO}_{4}$-intoxicated group.
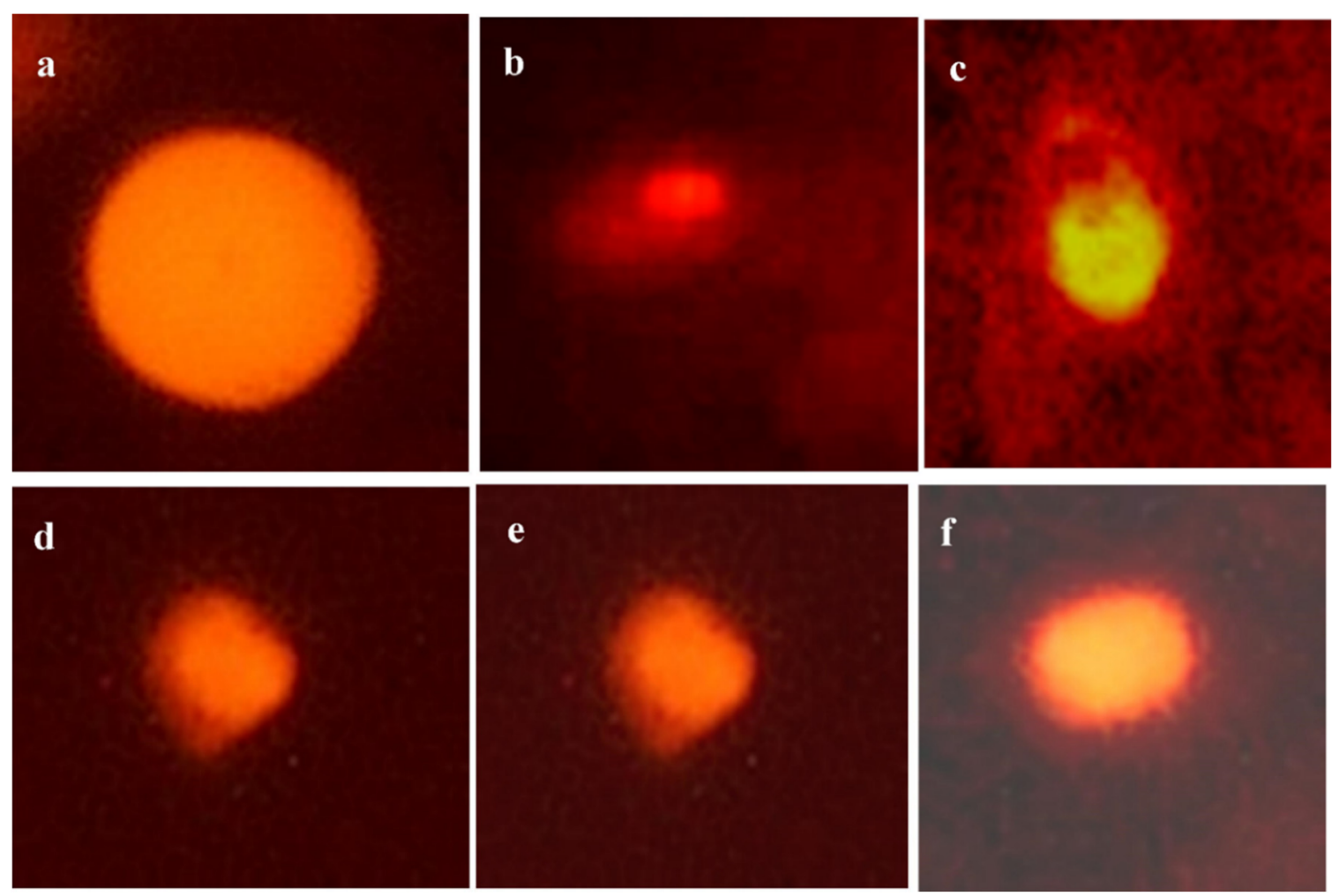

Figure 1. Electrophoresis of hepatic DNA samples of chicken from all experimental groups, using $1.2 \%$ ethidium bromidestained agarose $(\times 400)$. (a): The control group showed no DNA damage, as demonstrated by the lack of DNA fragment migration away from the nucleus core. $(\mathbf{b}, \mathbf{c})$ : $\mathrm{CuSO} 4$ group showed a high degree of DNA damage, with a significantly reduced nucleus core and a large cloud of DNA fragments migrating away from the core, forming the characteristic comet tail. (d): $\mathrm{CuSO}_{4}+$ Vit. $\mathrm{C}$ group showed a moderate degree of DNA damage. (e): $\mathrm{CuSO}_{4}+$ Vit. E group showed a reasonable degree of DNA damage. (f): $\mathrm{CuSO}_{4}+\mathrm{Vit} \mathrm{C}+\mathrm{Vit} \mathrm{E}$ group showed a minimal degree of DNA damage.

Table 7. Effect of single or combined supplementation of vitamin C and E on the DNA degradation indices in broiler chickens at the end of the 3rd week (Mean \pm SD).

\begin{tabular}{|c|c|c|c|c|c|c|}
\hline Parameters & $\mathrm{CON}$ & $\mathrm{CuSO}_{4}$ & $\mathrm{CuSO}_{4}+$ Vit. C & $\mathrm{CuSO}_{4}+$ Vit. E & $\mathrm{CuSO}_{4}+$ Vit. C + Vit. E & $p$-Value \\
\hline Comet \% & $13.38 \pm 1.17^{c}$ & $21.19 \pm 1.13^{\mathrm{a}}$ & $19.38 \pm 1.05^{\mathrm{ab}}$ & $18.96 \pm 2.00^{\mathrm{ab}}$ & $17.50 \pm 2.62^{b}$ & 0.000 \\
\hline DNA in tail $\%$ & $1.09 \pm 0.03^{\mathrm{e}}$ & $3.14 \pm 0.06^{\mathrm{a}}$ & $2.47 \pm 0.05^{\mathrm{b}}$ & $1.90 \pm 0.04^{c}$ & $1.34 \pm 0.06^{\mathrm{d}}$ & 0.009 \\
\hline Tail length (Pixel) & $1.14 \pm 0.02^{c}$ & $2.06 \pm 0.09^{a}$ & $1.92 \pm 0.03^{b}$ & $1.90 \pm 0.03^{b}$ & $1.88 \pm 0.02^{b}$ & 0.001 \\
\hline $\begin{array}{c}\text { Tail moment } \\
\text { (Arbitrary units) }\end{array}$ & $0.01 \pm 0.006^{\mathrm{e}}$ & $0.06 \pm 0.002^{\mathrm{a}}$ & $0.04 \pm 0.001^{b}$ & $0.03 \pm 0.001^{c}$ & $0.02 \pm 0.003^{\mathrm{d}}$ & 0.001 \\
\hline Olive tail moment & $0.15 \pm 0.05^{c}$ & $0.35 \pm 0.06^{\mathrm{a}}$ & $0.31 \pm 0.08^{\mathrm{a}}$ & $0.25 \pm 0.05^{b}$ & $0.27 \pm 0.03^{b}$ & 0.000 \\
\hline
\end{tabular}

$\mathrm{a}, \mathrm{b}, \mathrm{c}, \mathrm{d}, \mathrm{e}$ Means carrying different superscripts are significantly different at $p<0.05$. Values are expressed as $\%$ of total counts in each assay. 
Table 8. Effect of single or combined supplementation of vitamin C and $\mathrm{E}$ on the DNA degradation indices in broiler chickens at the end of the 6 th week (Mean \pm SD).

\begin{tabular}{ccccccc}
\hline Parameters & $\mathbf{C O N}$ & $\mathrm{CuSO}_{4}$ & $\mathrm{CuSO}_{4}+$ Vit. C & $\mathrm{CuSO}_{4}+$ Vit. E & CuSO $_{4}+$ Vit. C + Vit. E & $p$-Value \\
\hline Comet $\%$ & $14.56 \pm 1.69^{\mathrm{c}}$ & $25.90 \pm 2.14^{\mathrm{a}}$ & $23.95 \pm 1.50^{\mathrm{ab}}$ & $23.81 \pm 3.24^{\mathrm{ab}}$ & $19.95 \pm 2.95^{\mathrm{b}}$ & 0.000 \\
DNA in tail \% & $1.25 \pm 0.03^{\mathrm{e}}$ & $3.47 \pm 0.06^{\mathrm{a}}$ & $2.77 \pm 0.05^{\mathrm{b}}$ & $2.07 \pm 0.04^{\mathrm{c}}$ & $1.38 \pm 0.02^{\mathrm{d}}$ & 0.000 \\
Tail length (Pixel) & $1.99 \pm 0.08^{\mathrm{e}}$ & $3.00 \pm 0.10^{\mathrm{a}}$ & $2.70 \pm 0.13^{\mathrm{b}}$ & $2.50 \pm 0.10^{\mathrm{bc}}$ & $2.27 \pm 0.07^{\mathrm{d}}$ & 0.000 \\
Tail moment & $0.02 \pm 0.009^{\mathrm{e}}$ & $0.10 \pm 0.017^{\mathrm{a}}$ & $0.07 \pm 0.022^{\mathrm{b}}$ & $0.05 \pm 0.017^{\mathrm{c}}$ & $0.03 \pm 0.014^{\mathrm{d}}$ & 0.009 \\
(Arbitrary units) & $0.21 \pm 0.03^{\mathrm{c}}$ & $0.42 \pm 0.03^{\mathrm{a}}$ & $0.36 \pm 0.06^{\mathrm{b}}$ & $0.31 \pm 0.02^{\mathrm{b}}$ & $0.29 \pm 0.01^{\mathrm{b}}$ & 0.004 \\
Olive tail moment & $0.21 \pm 0$. & \\
\hline
\end{tabular}

$\mathrm{a}, \mathrm{b}, \mathrm{c}, \mathrm{d}, \mathrm{e}$ Means carrying different superscripts are significantly different at $p<0.05$. Values are expressed as $\%$ of total counts in each assay.

\subsection{Histopathological Findings}

The livers of the control chicken showed typical histological arrangement of hepatic lobules at the 3rd and 6th weeks (Figure 2a,b), respectively. In contrast, the livers of chicken from the $\mathrm{CuSO}_{4}$-intoxicated group displayed hyperplastic and necrotic biliary epithelium with various degenerative and necrotic changes at the third week (Figure 3a). Additionally, cholestasis, necrotic bile duct epithelia, besides lymphocytic portal aggregation and fibroblast proliferation, were encountered at the 6th week (Figure 4a). Liver from chicken of the $\mathrm{CuSO}_{4}+$ Vit. $\mathrm{C}$ group showed moderate enlargement of hepatic cells and hyperplastic Kupffer cells at the 3rd week (Figure 3b) and partially contracted hepatic cells proliferative Kupffer cells and dilated sinusoids at the 6th week (Figure 4b). Liver from chicken of the $\mathrm{CuSO}_{4}+$ Vit. E supplemented group revealed lymphocytic portal aggregations within apparently normal hepatic parenchyma at the third week (Figure 3c), while intense hyperplasia of Kupffer cells and cloudy swelling of hepatic cells with a few lymphocytic aggregations were seen at the 6th week (Figure 4c). Liver of the $\mathrm{CuSO}_{4}+$ Vit. C + Vit. E group displayed little portal and interstitial lymphocytic aggregations with apparently normal hepatic parenchyma at the third week (Figure 3d), mild portal lymphocytic aggregation, normal hepatic parenchyma, and dilated blood vessels were observed at the 6th week (Figure 4d).
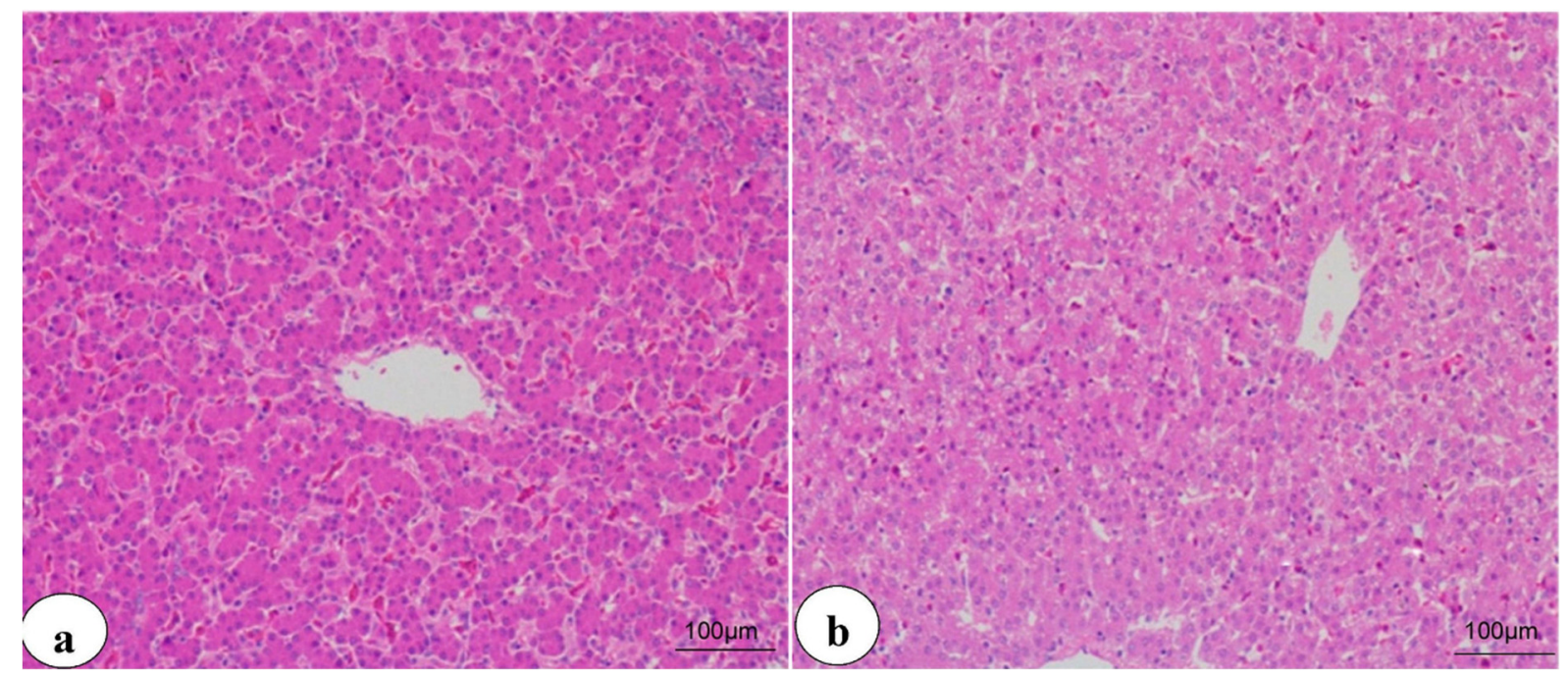

Figure 2. Photomicrographs of liver sections from chickens of the control group showed normal histopathological structures at the end of the 3rd week (a) and 6th week (b). 


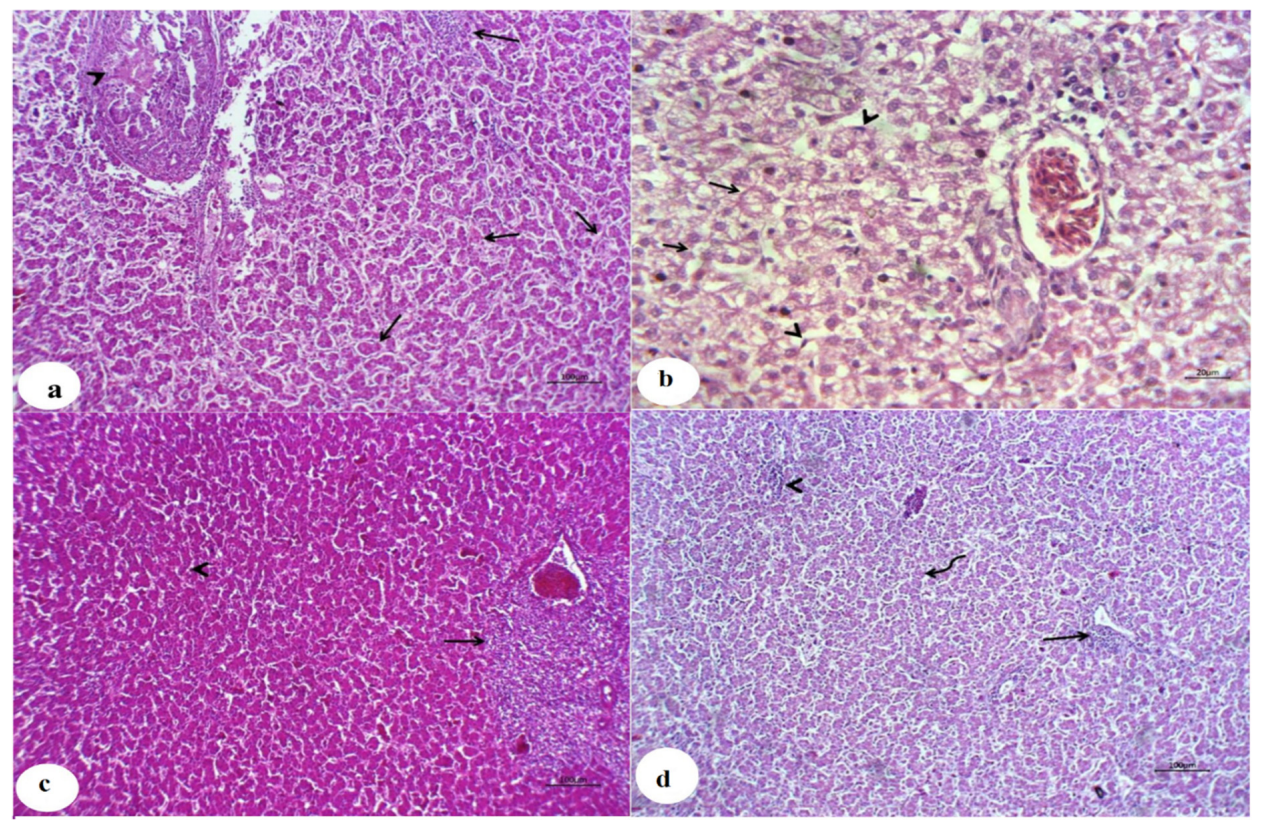

Figure 3. Photomicrographs of liver sections for chickens of all experimental groups at the end of the 3rd week. (a): Liver of $\mathrm{CuSO}_{4}$-intoxicated chicken showed hyperplastic and necrotic biliary epithelium (arrow) with various degenerative and necrotic changes in the hepatic cells (arrowhead). (b): Liver of $\mathrm{CuSO}_{4}+$ Vit. C group showed moderate swelling of hepatic cells (arrow) and hyperplastic Kupffer cells (arrowhead). (c): Liver of $\mathrm{CuSO}_{4}+$ Vit. E group showed lymphocytic portal aggregation (arrow) within apparently normal hepatic parenchyma (arrowhead). (d): Liver of $\mathrm{CuSO}_{4}+$ Vit. C + Vit. E group showed little portal (arrow) and interstitial lymphocytic aggregations within apparently normal hepatic parenchyma (arrowhead).

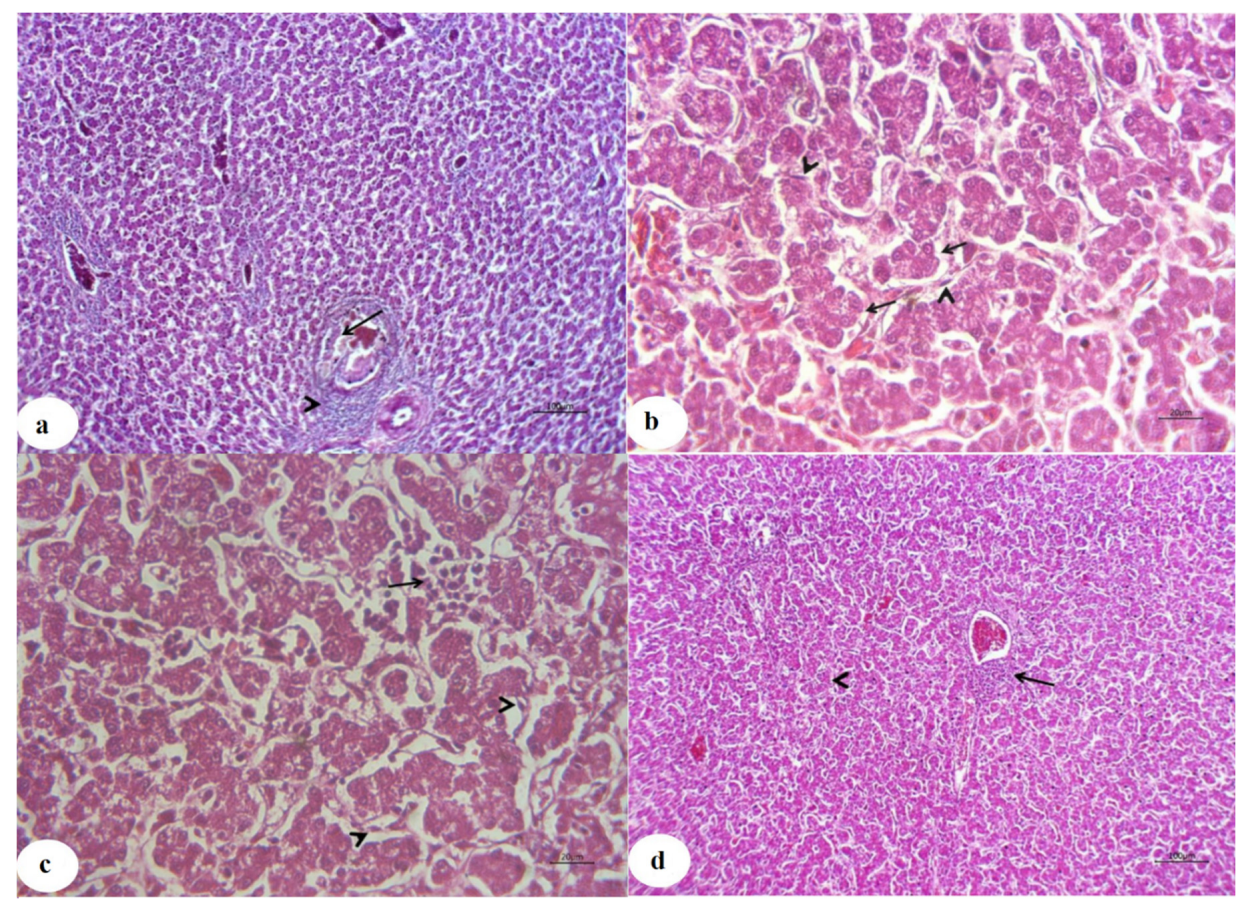

Figure 4. Photomicrographs of liver sections for chickens of all experimental groups at the end of the 6th week. (a): Liver of $\mathrm{CuSO}_{4}$-intoxicated chicken showed cholestasis, necrotic bile duct epithelia (arrow), besides portal lymphocytic aggregation and fibroblast proliferation (arrowhead). (b): Liver of $\mathrm{CuSO}_{4}+$ Vit. C supplemented chicken showed partially contracted hepatic cells (arrow), proliferative Kupffer cells, and dilated sinusoids (arrowhead). (c): Liver of CuSO $4+$ Vit. E supplemented chicken showed intense hyperplasia of Kupffer cells (arrowhead) and cloudy swelling of hepatic cells with a few lymphocytic aggregations (arrow). (d): Liver of $\mathrm{CuSO}_{4}+$ Vit. C + Vit. E supplemented chicken showed mild portal lymphocytic aggregation (arrow) and normal hepatic parenchyma (arrowhead) with dilated blood vessels. 


\section{Discussion}

Although the level of copper up to 100 to $200 \mathrm{mg} / \mathrm{kg}$ as $\mathrm{CuSO}_{4}$ improves growth performance in the broilers [9,35-37], incompatible effects such as poor feed intake, decrease in body weight, and hematobiochemical changes at higher doses of copper have been reported [38-40]. In this study, no clinical signs or mortality were perceived during the experimental period in Vit. $\mathrm{C}$ and $\mathrm{E}$ supplemented groups, while $\mathrm{CuSO}_{4}$-intoxicated birds showed mild diarrhea, anorexia, and weight reduction. This was synchronized with Luo et al. [41], who reported zero mortality in male chicks supplemented with 300 and 450 $\mathrm{mg} / \mathrm{kg} \mathrm{CuSO}$ for 21 days. Other studies reported no significant differences in mortality \% of broiler chickens among the control and other groups given $0,10,25,50,125,250$, and 500 $\mathrm{CuSO}_{4} / \mathrm{kg}$ diet for 35 days [42] or 100, 200, and $400 \mathrm{mg} \mathrm{CuSO} / \mathrm{kg}$ diet for 42 days [43].

The exiting investigation showed that copper sulfate had a toxic effect, as exhibited by a statistical reduction in growth efficiency parameters (BW, BWG, and FI), increasing the FCR over the entire growth-out period (days 1-42) in $\mathrm{CuSO}_{4}$-intoxicated birds. These findings may be attributed to falling in the feed intake and utilization as a result of GIT disturbance caused by a highly toxic dose of $\mathrm{Cu}$ or owing to the embarrassment of the satiety center by $\mathrm{Cu}$, leading to loss of interest in feeding [44]. Additionally, the reduction in feed consumption could be due to an anorexic effect of $\mathrm{CuSO}_{4}$ on chickens [41,45]. Our results were consistent with Luo et al. [41], Cinar et al. [17], Abduljaleel [46], Scott et al. [36], and Zhou et al. [47]. Previous studies recorded different outcomes such as unchanged BW and FCR in chicks fed up to $400 \mathrm{mg} \mathrm{Cu} / \mathrm{kg}$ [48] and improved live weight gain in broiler chick supplemented with $400 \mathrm{mg} / \mathrm{kg}$ feed copper sulfate for 6 weeks [43]. The reason for variances between our experimental results and others may be concurrent with the varieties in the $\mathrm{CuSO} 4$ particle size, stain, and age of birds, experimental periods, and the dose of copper between earlier and current experiments. Furthermore, the difference between the effects of $\mathrm{Cu}$ levels on the growth performance of raising poultry indicates that the bioavailability of $\mathrm{Cu}$ can differ. This was supported by other literature stating that copper at sufficient dietary levels has favorable impacts, but severe toxic effects as a result of extra copper are well established [49,50]. The study of Morsy et al. [51] investigated the oral administration of copper oxide nanoparticles (CuO-NPs) at doses $5 \mathrm{mg} / \mathrm{kg}$ and $15 \mathrm{mg} / \mathrm{kg}$ BW in broiler chickens. They showed a notable decrease in weight gain, FCR in a level-dependent manner. The growth parameters were upgraded meaningfully in $\mathrm{CuSO}_{4}$ + Vit. $\mathrm{C}$ and $\mathrm{CuSO}_{4}+$ Vit. E-supplemented groups compared to $\mathrm{CuSO}_{4}$-intoxicated group; however, better results have been found in birds taking both Vit. $\mathrm{C}$ and Vit E. Many reports showed better performance by feeding Vit. C or Vit. E to broiler chicks [17,46,52-54] or fish [55-59]. The improvements in performance characteristics in vitamin-supplemented groups could be attributable to their antioxidant effects that protect the bird from the oxidative stress caused by $\mathrm{Cu}$ exposure $[60,61]$ or the role of vitamins as an immune stimulant [62].

Birds supplemented with excess $\mathrm{CuSO}_{4}$ revealed an elevation in serum transaminases (ALT and AST) and ALP activities correlated with diminished serum TP, albumin, and globulins levels equated to the control group, suggesting significant liver damage (hepatotoxicity), which was established by hyperplastic and necrotic biliary epithelium, hepatic degeneration, and necrosis in the histopathological findings. The increased transaminase activities in the $\mathrm{CuSO}_{4}$-intoxicated group may be associated with the influence of $\mathrm{Cu}$ on the liver and kidney, so releasing their intracellular enzymes to circulation [63] or due to the cytotoxic effect of $\mathrm{Cu}$, resulting in lipid peroxidation indicating the hepatotoxic effect of $\mathrm{Cu}$ [64]. In addition, Kumar et al. [43] determined that a higher level of copper accumulation may have injured the liver to rise these enzymes. Abundant studies indicate that copper can be metabolized in hepatic tissues and converted by glutathione (GSH) into metallothionein; Therefore, copper excess is got, and the immediate results of GSH are depleted of enhanced cytotoxicity [65].The finding of high serum enzymes in Cu-intoxicated broilers agreed with Yigit et al. [49], who stated that copper produced changes in the liver transaminases of broilers. As a result of $\mathrm{CuSO}_{4}$ addition, the upsurge in ALP activity might 
be recognized for liver, intestine, kidney, and to some degree, bile duct injuries, especially liver cell membrane, which appears to act as a stimulus to increase the synthesis of this enzyme or may be due to hepatic or bile duct cholestasis causing enzyme regurgitation back into the bloodstream [66].

The reported hypoproteinemia in this inquiry may be due to impairment protein synthesis or the functional deterioration of the liver and excessive loss of protein caused by nephrosis [67] or could be explained due to the oxidative stress of copper on the liver and kidney tissue [11,39]. Since albumin has unique copper ion binding sites and carries dietary copper to the liver [68], the distinguished drop in the serum albumin levels may be due to the decrease in the synthesis of hepatic albumin in the $\mathrm{CuSO}_{4}$ group. Contrary to our results, Almansour [69] reported intensification in serum protein levels in copper-fed quail. Cinar et al. [17] displayed no alteration in plasma proteins of $300 \mathrm{mg} / \mathrm{kg}$ diet copper-fed bird. Dietary addition of Vit. C and Vit. E alone or in combination with $\mathrm{CuSO}_{4}$-intoxicated birds significantly ameliorated the previous changes in liver enzymes, demonstrating that these vitamins have potential protecting effects on cell membranes, thus preventing enzyme leak into the blood $[17,70]$. Better results were evident with vitamin supplementation than each alone because some liver biomarkers were returned near the average control values. These results were in synchronization with those attained by [71], Abou-Kassem et al. [72], Mashkoor et al. [73], and Hashem et al. [20]. The hepatoprotective influence of vitamin C or $\mathrm{E}$ is associated with their antioxidant properties [74]. Additionally, ascorbic acid causes its association with heavy metals, which leads to reduced tissue oxidative stress and restored AST, ALT, ALP and LDH levels [75]. Besides, vitamins C and E may preserve the hepatic cellular membrane and protect hepatocyte from copper's toxic effects, minimizing the enzyme's leakage into the bloodstream [70]. In dissimilarity, supplementing cadmiumintoxicated broilers with vitamins $\mathrm{C}$ and $\mathrm{E}$ did not recover transaminase activities [76].

Co-supplementation of copper with Vit. $\mathrm{C}$ and Vit. E alone or in combination elevated serum TP, albumin, globulins. The enhancement in the protein profile in $\mathrm{Cu}$-exposed birds fed with Vit. C and Vit. E alone or in combination may be due to the immunostimulant effect [77] or due to impairments of the copper uptake and utilization [17] by dietary supplement of Vit. C or Vit. E. Imik et al. [78] reported a high total protein concentration in blood of quail supplemented vitamin $\mathrm{E}$ and $\mathrm{C}$ in the diet. Therefore, only the coadministration of copper with both vitamins had a protecting effect to hepatotoxicity caused by $\mathrm{CuSO}_{4}$.

Regarding lipogram analysis, $\mathrm{CuSO}_{4}$ administration causes dyslipidemia, evidenced by a numerical reduction in serum TG, TC, LDL-C, and VLDL-C levels; however, serum HDL-C did not display any change in the third week but significantly dropped at 6th week in $\mathrm{CuSO}_{4}$-intoxicated birds compared with the control group. Our findings were consistent with Bakalli et al. [79] and Idowu et al. [71]. Moreover, Wu et al. [80] noticed significantly lessened serum cholesterol and LDL-C levels in broilers fed 3 sources of copper (copper methionate, tribasic copper chloride, and copper sulfate) in the diet. The reduction in plasma cholesterol and triacylglycerol in the blood of $\mathrm{Cu}$-exposed chickens is due to fall cholesterol synthesis, high degradation, or excretion rates [81]. The excess level of $\mathrm{Cu}$ supplementation to diet either declines GSH that diminished stimulation of HMG-CoA reductase activity resulted in the reduced synthesis of cholesterol [82], or lead to changes in lipid metabolism, which result in decreasing plasma lipid, 17 beta-estradiol, and hepatic lipogenic enzyme activity [83]. The reduction in LDL level was related to copper toxicity because $\mathrm{Cu}$ is an effective catalyst of LDL-C oxidation to an atherogenic form [84] or alkoxyl radicals [85]. The reduction in HDL-C is due to hypocholesterolemia and hypoproteinemia in this inquiry, as more than $40 \%$ of HDL-C value represents cholesterol value and the remaining proteins [86]. The same findings were obtained by El-Hady and Mohamed [87] in broiler chickens with dietary supplementation of $\mathrm{CuSO}_{4}$ at levels 50 and $100 \mathrm{ppm}$ for 5 weeks. However, earlier studies exposed different outcomes, for example, rise of total lipid, cholesterol, and LDL-C with no variation HDL-C level in Cu-exposed quail [69] or no alteration in plasma total cholesterol levels in broilers [17]. Additionally, Jegede et al. [35] 
informed a decrease in plasma triglycerides and cholesterol in Arbor-Acre unsexed broilers fed $\mathrm{CuSO}_{4}$ or copper proteinate at concentrations of 50,100, or $150 \mathrm{mg} / \mathrm{kg}$ diet for 56 days. The breed, dietary components, and the investigational strategy and methodology can explain these differences.

Dietary supplementations of $\mathrm{CuSO}_{4}$-intoxicated birds with Vit. $\mathrm{C}$ and Vit. E alone or in combination reduce the opposing effects of copper on lipid profile. Treatment of $\mathrm{Cu}$ toxicity with Vit. $C$ and Vit. E combination is more effective than using each one separately. This can be due to the ability of the vitamin $C$ to replenish the vitamin $E$ re-mobilizes the free radicals associated with it [88]. The combination of vitamins protects lipid structures against peroxidation [70]. Vitamin $\mathrm{C}$ guards against $\mathrm{Cu}$ toxicity by preventing excess $\mathrm{Cu}$ absorption by minimizing copper absorption from the intestine by reducing soluble $\mathrm{Cu}$ levels in the small intestine $[89,90]$. Besides, Vit. E can prevent cholesterol-related endothelial dysfunction, preventing functional impairment induced by ROS [13].

Although the micronucleus assay has been useful and its utility should be considered [91], the comet assay is a more sensitive method for assessing genotoxicity [92]. The true comet assay was used to test for genotoxic agents [93]. Collaboration with others is a sensitive and fast method for distinguishing DNA damage produced by trace metals, such as copper [94].

Data from this research showed that $\mathrm{CuSO}_{4}$ has the genotoxic ability to interact with DNA and induce mammalian cell alterations specified by elevation in comet \%, DNA $\%$ in the tail, tail length, tail moment, and olive tail moment. Similarly, Banu et al. [95] indicated significant DNA damage with a decrease in mean comet tail-length after adding $\mathrm{CuSO}_{4}$. Copper-induced DNA damage may or may not be constrained at low copper concentrations, as it is closely bound to storage or transport proteins (eg. ceruloplasmin) and thus not available for oxidative reactions [96], but at high concentrations, free $\mathrm{Cu}$ can have an enormous genotoxic effect [91]. Free $\mathrm{Cu}$ causes ROS and multiple types of DNA damage, such as base alteration and DNA strand breaks, which can cause severe cell death [97]. A copper-induced high ROS production consequence in oxidative destruction to a single DNA base and sugar phosphate and breaks DNA strands [98]. Additionally, copper reduces DNA-binding cell viability, resulting in cell death [99].

The current study revealed that supplementing of $\mathrm{CuSO}_{4}$-intoxicated chickens with Vit. $\mathrm{C}$ and Vit. E alone or in combination exert a partial genoprotective effect against DNA damage induced by excessive concentrations of copper, which was proved by the decrease of comet $\%$, tail length, and moment. A combination of vitamins is more effective in reducing the genotoxic effects of copper than using each vitamin alone. The genoprotective effect of Vit. C and Vit. E could act as free radical scavengers and antioxidants [100]. Jiraungkoorskul and Sahaphong [101] demonstrated that ascorbic acid reduces genotoxicity in fish induced by copper. Assy et al. [102] exhibited a defending effect of Vit. E (100 mg/kg diet) against DNA damage in rats with $\mathrm{CuO}$ nanoparticles toxicity $(250 \mathrm{mg} / \mathrm{kg}$ diet). Our outcomes are in settlement with a new study reporting potential anticipatory effects of dietary antioxidants, including vitamin E, ascorbic acid, phytosterols, polyphenols, and medicinal plants extracts against vanadium-induced DNA damage [103]. Another study showed that curcumin supplementation reduced genomic and cellular DNA damage in mice exposed to $390 \mathrm{ppm} \mathrm{Cu}$ [91]. Morsy et al. [51] reported increased DNA fragmentation percent and microscopic recording in various inspected organs of chickens received $\mathrm{CuO}$ NPs.

Histopathological check established the results of $\mathrm{CuSO}_{4}$-intoxicated chickens in the existing inquest and it is in coordination with the earlier report of Oguz et al. [38], Shahzad et al. [40], Wang et al. [11] in chickens and Baruah et al. [104] in ducks with copper toxicity. Similarly, other studies exhibited a significant inflammatory cell infiltration and hepatocyte vacuolar degeneration [105], severe microscopic changes, including vacuolar degeneration, local tissue necrosis, and blurred hepatic lobules in birds-supplemented with $300 \mathrm{mg}$ $\mathrm{Cu} / \mathrm{kg}$ diet [47]. Morsy et al. [51] observed histopathological changes in chickens getting $\mathrm{CuO}-\mathrm{NPs}$ with some differences in its severity. Our results differ from other findings that 
showed that birds fed a high level of copper diet did not alter any histological tissue [106]. These inappropriate associations may be attributed to the variance in the types of test subjects, experimental animals, and test duration. Long-term exposure of birds to high levels of copper, dangerous effects may occur [47]. However, single or combined addition with Vit. C and Vit. E decreased the histopathological alterations with apparently typical liver architecture in some cases. Other findings presented that the addition of vitamins $C$ and $E$ in the feed has successfully offset arsenite's toxic effects in broiler chicken [107].

\section{Conclusions}

The obtained findings could conclude that long-term exposure to $\mathrm{CuSO}_{4}$ caused significant alterations in the liver evaluation biomarkers, genotoxicity, and histopathology. Dietary addition of vitamins $\mathrm{C}$ and $\mathrm{E}$ reduced the harmful effects induced by $\mathrm{CuSO}_{4}$, especially with their combination, which caused an improvement in the growth performance; returned the biochemical parameters in close to average values, with subsidence the histopathological changes and DNA degeneration. Overall, the protective roles of vitamins $C$ and $E$ with their synergistic action against the toxic effects of $C u$ are seen in our research, but further studies are still needed to understand the full potential of vitamins.

Author Contributions: M.A.H.: conceptualization, methodology, visualization, writing-review and editing. S.S.A.E.H.: conceptualization, methodology, resources, software, formal analysis, investigation, data curation, visualization, writing-original draft. E.M.A.A.: conceptualization, methodology, visualization, writing-review and editing. S.A.A.: conceptualization, methodology, writing-review and editing. M.E.E.-S.: conceptualization, funding acquisition. All authors have read and agreed to the published version of the manuscript.

Funding: The work was funded by Taif University Researchers Supporting Project (TURSP-2020/139), Taif University, Taif, Saudi Arabia.

Institutional Review Board Statement: The ethics of the experimental protocol were approved by the Institutional Animal Care and Use Committee of Zagazig University, Egypt (ZU-IACUC/2020). All animal experiments were performed following the recommendations described in "The Guide for the Care and Use of Laboratory Animals in scientific investigations".

Informed Consent Statement: Not applicable.

Data Availability Statement: Data sharing not applicable.

Acknowledgments: This work was carried out using the facilities and materials in Taif University Researches Supporting Project number (TURSP-2020/139), Taif University, Taif, Saudi Arabia. The authors would like to express gratitude to Abd-ELmonem A. Ali, Professor of Pathology, Faculty of Veterinary Medicine, Zagazig University, for his valuable help in histopathological studies.

Conflicts of Interest: The authors declare no conflict of interest.

\section{References}

1. Samanta, B.; Biswas, A.; Ghosh, P. Effects of dietary copper supplementation on production performance and plasma biochemical parameters in broiler chickens. Br. Poult. Sci. 2011, 52, 573-577. [CrossRef]

2. Spatari, S.; Bertram, M.; Fuse, K.; Graedel, T.E.; Rechberger, H. The contemporary European copper cycle: 1 year stocks and flows. Ecol. Econom. 2002, 42, 27-42. [CrossRef]

3. Ozcelik, D.; Ozaras, R.; Gurel, Z.; Uzun, H.; Aydin, S. Copper-mediated oxidative stress in rat liver. Biol. Trace Element Res. 2003, 96, 209-215. [CrossRef]

4. Wang, Y.; Zhao, H.; Shao, Y.; Liu, J.; Li, J.; Luo, L.; Xing, M. Copper (II) and/or arsenite-induced oxidative stress cascades apoptosis and autophagy in the skeletal muscles of chicken. Chemosphere 2018, 206, 597-605. [CrossRef]

5. Yruela, I. Copper in plants. Brazil. J. Plant Physiol. 2005, 17, 145-156. [CrossRef]

6. NRC. Copper in Drinking Water; National Academy Press: Washington, DC, USA, 2000.

7. Linder, M.C.; Hazegh-Azam, M. Copper biochemistry and molecular biology. Am. J. Clin. Nutr. 1996, 63, 797S-811S. [PubMed]

8. Liu, H.; Guo, H.; Jian, Z.; Cui, H.; Fang, J.; Zuo, Z.; Deng, J.; Li, Y.; Wang, X.; Zhao, L. Copper induces oxidative stress and apoptosis in the mouse liver. Oxid. Med. Cell. Longev. 2020, 2020, 1359164. [CrossRef] 
9. Lu, L.; Wang, R.L.; Zhang, Z.J.; Steward, F.A.; Luo, X.; Liu, B. Effect of dietary supplementation with copper sulfate or tribasic copper chloride on the growth performance, liver copper concentrations of broilers fed in floor pens, and stabilities of vitamin $\mathrm{E}$ and phytase in feeds. Biol. Trace Element Res. 2010, 138, 181-189. [CrossRef]

10. Zhao, L.; Cui, H.; Yang, F.; Peng, X.; Deng, J. Effects of high dietary copper on hepatic oxidation and hepatocyte apoptosis in ducklings. Chin. Vet. Sci. 2008, 38, 54-58.

11. Wang, Y.; Zhao, H.; Shao, Y.; Liu, J.; Li, J.; Xing, M. Copper or/and arsenic induce oxidative stress-cascaded, nuclear factor kappa B-dependent inflammation and immune imbalance, trigging heat shock response in the kidney of chicken. Oncotarget 2017, 8 , 98103. [CrossRef]

12. Świątkiewicz, S.; Arczewska-Włosek, A.; Jozefiak, D. The efficacy of organic minerals in poultry nutrition: Review and implications of recent studies. World Poult. Sci. J. 2014, 70, 475-486. [CrossRef]

13. Gaetke, L.M.; Chow, C.K. Copper toxicity, oxidative stress, and antioxidant nutrients. Toxicology 2003, 189, 147-163. [CrossRef]

14. Ajuwon, O.R.; Idowu, O. Vitamin C attenuates copper-induced oxidative damage in broiler chickens. Afr. J. Biotechnol. 2010, 9 , 7525-7530.

15. Vantress, C. Cobb Broiler Management Guide. 2012. Available online: https://www.cobb-vantress.com/assets/5c7576a214 /Broiler-guide-R1.pdf (accessed on 2 April 2021).

16. Giambrone, J.; Clay, R.P. Vaccination of day-old broiler chicks against Newcastle disease and infectious bursal disease using commercial live and/or inactivated vaccines. Avian Diseases 1986, 30, 557-561. [CrossRef]

17. Cinar, M.; Yildirim, E.; Yigit, A.A.; Yalcinkaya, I.; Duru, O.; Kisa, U.; Atmaca, N. Effects of dietary supplementation with vitamin $\mathrm{C}$ and vitamin $\mathrm{E}$ and their combination on growth performance, some biochemical parameters, and oxidative stress induced by copper toxicity in broilers. Biol. Trace Element Res. 2014, 158, 186-196. [CrossRef]

18. Sahin, K.; Sahin, N.; Yaralioglu, S. Effects of vitamin C and vitamin E on lipid peroxidation, blood serum metabolites, and mineral concentrations of laying hens reared at high ambient temperature. Biol. Trace Element Res. 2002, 85, 35-45. [CrossRef]

19. Amer, S.A.; Al-Khalaifah, H.S.; AlSadek, D.M.; Roushdy, E.M.; Sherief, W.R.; Farag, M.F.; Altohamy, D.E.; Abdel-Wareth, A.A.; Metwally, A.E. Effect of Dietary Medium-Chain $\alpha$-Monoglycerides on the Growth Performance, Intestinal Histomorphology, Amino Acid Digestibility, and Broiler Chickens' Blood Biochemical Parameters. Animals 2021, 11, 57. [CrossRef] [PubMed]

20. Hashem, M.; Gamal El-Dein, I.; Eltahawy, S. Clinicopathological studies on the ameliorative effects of selenium and vitamin E against cadmium toxicity in chickens. Zagazig Vet. J. 2019, 47, 277-287. [CrossRef]

21. Association, A.V.M. AVMA Guidelines for the Euthanasia of Animals: 2013 Edition; American Veterinary Medical Association: Schaumburg, IL, USA, 2013.

22. Reitman, S.; Frankel, S. A colorimetric method for the determination of serum glutamic oxalacetic and glutamic pyruvic transaminases. Am. J. Clin. Pathol. 1957, 28, 56-63. [CrossRef]

23. Moss, D.W. Alkaline phosphatase isoenzymes. Clin. Chem. 1982, 28, 2007-2016. [CrossRef]

24. Grant, G. Amino acids and proteins. In Fund Clinical Chemistry; Academic Press: New York, NY, USA, 1987.

25. Doumas, B.; Baysa, D.; Carter, R.; Peters, T.; Schaffer, R. Determination of serum total protein. Clin. Chem. 1981, $27,1642$. [CrossRef] [PubMed]

26. Doumas, B.; Biggs, H. Determination of Serum Albumin in Standard Method of Clinical Chemistry; Cooper, G.R., Ed.; Academic Press: New York, NY, USA, 1972; Volume 7.

27. Zöllner, N.; Kirsch, K. Über die quantitative Bestimmung von Lipoiden (Mikromethode) mittels der vielen natürlichen Lipoiden (allen bekannten Plasmalipoiden) gemeinsamen Sulfophosphovanillin-Reaktion. Zeit. Ges. Exp. Med. 1962, 135, 545-561. [CrossRef]

28. Roeschlau, P.; Bernt, E.; Gruber, W. Enzymatic determination of total cholesterol in serum (author's transl). Zeit. Klin. Chem. klin. Biochem. 1974, 12, 403-407.

29. McGowan, M.W.; Artiss, J.D.; Strandbergh, D.R.; Zak, B. A peroxidase-coupled method for the colorimetric determination of serum triglycerides. Clin. Chem. 1983, 29, 538-542. [CrossRef]

30. Young, D. Effects of Disease on Clinical Lab Tests, 4th ed.; Young, D.S., Friedman, R.B., Eds.; AACC Press: Washington, DC, USA, 2001.

31. Friedewald, W.T.; Levy, R.I.; Fredrickson, D.S. Estimation of the concentration of low-density lipoprotein cholesterol in plasma, without use of the preparative ultracentrifuge. Clin. Chem. 1972, 18, 499-502. [CrossRef] [PubMed]

32. Singh, N.P.; McCoy, M.T.; Tice, R.R.; Schneider, E.L. A simple technique for quantitation of low levels of DNA damage in individual cells. Exp. Cell Res. 1988, 175, 184-191. [CrossRef]

33. Suvarna, K.S.; Layton, C.; Bancroft, J.D. Bancroft's Theory and Practice of Histological Techniques E-Book; Elsevier Health Sciences: Amsterdam, The Netherlands, 2018.

34. Duncan, D.B. Multiple range and multiple F tests. Biometrics 1955, 11, 1-42. [CrossRef]

35. Jegede, A.; Oduguwa, O.; Bamgbose, A.; Fanimo, A.; Nollet, L. Growth response, blood characteristics and copper accumulation in organs of broilers fed on diets supplemented with organic and inorganic dietary copper sources. Br. Poult. Sci. 2011, 52, 133-139. [CrossRef]

36. Scott, A.; Vadalasetty, K.; Łukasiewicz, M.; Jaworski, S.; Wierzbicki, M.; Chwalibog, A.; Sawosz, E. Effect of different levels of copper nanoparticles and copper sulphate on performance, metabolism and blood biochemical profiles in broiler chicken. J. Anim. Physiol. Anim. Nutr. 2018, 102, e364-e373. [CrossRef] 
37. Nguyen, H.; Morgan, N.; Roberts, J.; Swick, R.; Toghyani, M. Copper hydroxychloride is more efficacious than copper sulfate in improving broiler chicken's growth performance, both at nutritional and growth-promoting levels. Poult. Sci. 2020, 99, 6964-6973. [CrossRef]

38. Oguz, E.O.; Yuksel, H.; Enli, Y.; Tufan, A.C.; Turgut, G. The effects of copper sulfate on liver histology and biochemical parameters of term ross broiler chicks. Biol. Trace Element Res. 2010, 133, 335-341. [CrossRef] [PubMed]

39. Oğuz, E.; Enli, Y.; Tufan, A.; Turgut, G. Toxic effects of copper sulfate on the brains of term Hubbard broiler chicks: A stereological and biochemical study. Biotech. Histochem. 2014, 89, 23-28. [CrossRef] [PubMed]

40. Shahzad, M.N.; Javed, M.T.; Shabir, S.; Irfan, M.; Hussain, R. Effects of feeding urea and copper sulphate in different combinations on live body weight, carcass weight, percent weight to body weight of different organs and histopathological tissue changes in broilers. Exp. Toxicol. Pathol. 2012, 64, 141-147. [CrossRef]

41. Luo, X.; Ji, F.; Lin, Y.; Steward, F.; Lu, L.; Liu, B.; Yu, S. Effects of dietary supplementation with copper sulfate or tribasic copper chloride on broiler performance, relative copper bioavailability, and oxidation stability of vitamin E in feed. Poult. Sci. 2005, 84, 888-893. [CrossRef] [PubMed]

42. Wang, Z.; Cerrate, S.; Coto, C.; Yan, F.; Waldroup, P. Evaluation of Mintrex copper as a source of copper in broiler diets. Int J Poult Sci 2007, 6, 308-313. [CrossRef]

43. Kumar, P.; Biswas, A.; Bharti, V.; Srivastava, R. Effects of dietary copper supplementation on performance and blood biochemical parameters in broiler chickens at cold desert region in India. J. Vet. Sci. Photon 2013, 114, 166-172.

44. Asmatullah, A.; Asma, A.; Latif, A.; Shakoori, A. Effect of hexavalent chromium on egg laying capacity, hatchability of eggs, thickness of egg shell and post-hatching development of Gallus domesticus. Asian Aust. J. Anim. Sci. 1999, 12, 944-950. [CrossRef]

45. Kim, J.; Kim, J.; Shin, J.; Kil, D.Y. Relative bioavailability of copper in tribasic copper chloride to copper in copper sulfate for laying hens based on egg yolk and feather copper concentrations. Poult. Sci. 2016, 95, 1591-1597. [CrossRef]

46. Abduljaleel, S.A. Toxicity Of Copper And Cobalt In Chicken (Gallus Gallus Domestics Assessment Of Body Weight And Metal Content In Tissues After Metal Dietary Supplements. Bas. J. Vet. Res. 2016, 15, 71-82. [CrossRef]

47. Zhou, Q.; Zhu, J.; Liu, B.; Qiu, J.; Lu, X.; Curtin, B.; Ji, F.; Yu, D. Effects of High-Dose of Copper Amino Acid Complex on Laying Performance, Hematological and Biochemical Parameters, Organ Index, and Histopathology in Laying Hens. Biol. Trace Element Res. 2020, 1-8. [CrossRef]

48. Miles, R.; O'keefe, S.; Henry, P.; Ammerman, C.; Luo, X. The effect of dietary supplementation with copper sulfate or tribasic copper chloride on broiler performance, relative copper bioavailability, and dietary prooxidant activity. Poult. Sci. 1998, 77, 416-425. [CrossRef]

49. Yigit, A.; Cinar, M.; Yildirim, E. The effects of levamisole on oxidative stress induced by copper intoxication in broilers. N. Z. Vet. J. 2012, 60, 273-277. [CrossRef]

50. Funk, M.; Baker, D. Toxicity and tissue accumulation of copper in chicks fed casein and soy-based diets. J. Anim. Sci. 1991, 69, 4505-4511. [CrossRef]

51. Morsy, E.A.; Hussien, A.M.; Ibrahim, M.A.; Farroh, K.Y.; Hassanen, E.I. Cytotoxicity and genotoxicity of copper oxide nanoparticles in chickens. Biol. Trace Element Res. 2021, 1-15. [CrossRef]

52. Zhu, Y.; Li, S.; Sun, Q.; Yang, X. Effect of in ovo feeding of vitamin C on antioxidation and immune function of broiler chickens. Animal 2019, 13, 1927-1933. [CrossRef] [PubMed]

53. Gouda, A.; Amer, S.A.; Gabr, S.; Tolba, S.A. Effect of dietary supplemental ascorbic acid and folic acid on the growth performance, redox status, and immune status of broiler chickens under heat stress. Trop. Anim. Health Prod. 2020, 52, 2987-2996. [CrossRef]

54. Amer, S.A.; Mohamed, W.A.; Gharib, H.S.; Al-Gabri, N.A.; Gouda, A.; Elabbasy, M.T.; Abd El-Rahman, G.I.; Omar, A.E. Changes in the growth, ileal digestibility, intestinal histology, behavior, fatty acid composition of the breast muscles, and blood biochemical parameters of broiler chickens by dietary inclusion of safflower oil and vitamin C. BMC Vet. Res. 2021, 17, 1-18. [CrossRef] [PubMed]

55. Azeez, O.; Braimah, S. Mitigating Effect of Vitamin-E on Copper Sulphate-Induced Toxicity in African Catfish (Clarias gariepinus). Eur. J. Med. Health Sci. 2020, 2, 411. [CrossRef]

56. Khara, H.; Sayyadborani, M.; SayyadBorani, M. Effects of $\alpha$-tocopherol (vitamin E) and ascorbic acid (vitamin C) and their combination on growth, survival and some haematological and immunological parameters of Caspian brown trout, Salmo Trutta Caspius juveniles. Turk. J. Fish. Aquat. Sci. 2016, 16, 385-393. [CrossRef]

57. Ibrahim, R.E.; Ahmed, S.A.; Amer, S.A.; Al-Gabri, N.A.; Ahmed, A.I.; Abdel-Warith, A.-W.A.; Younis, E.-S.M.; Metwally, A.E Influence of vitamin $C$ feed supplementation on the growth, antioxidant activity, immune status, tissue histomorphology, and disease resistance in Nile tilapia, Oreochromis niloticus. Aquacult. Rep. 2020, 18, 100545. [CrossRef]

58. Ahmed, S.A.; Ibrahim, R.E.; Farroh, K.Y.; Moustafa, A.A.; Al-Gabri, N.A.; Alkafafy, M.; Amer, S.A. Chitosan vitamin E nanocomposite ameliorates the growth, redox, and immune status of Nile tilapia (Oreochromis niloticus) reared under different stocking densities. Aquaculture 2021, 541, 736804. [CrossRef]

59. Ibrahim, R.E.; Amer, S.A.; Farroh, K.Y.; Al-Gabri, N.A.; Ahmed, A.I.; El-Araby, D.A.; Ahmed, S.A. The effects of chitosan-vitamin $\mathrm{C}$ nanocomposite supplementation on the growth performance, antioxidant status, immune response, and disease resistance of Nile tilapia (Oreochromis niloticus) fingerlings. Aquaculture 2021, 534, 736269. [CrossRef]

60. Gao, J.; Lin, H.; Wang, X.; Song, Z.; Jiao, H. Vitamin E supplementation alleviates the oxidative stress induced by dexamethasone treatment and improves meat quality in broiler chickens. Poult. Sci. 2010, 89, 318-327. [CrossRef] [PubMed] 
61. Selim, N.; Youssef, S.; Abdel-Salam, A.; Nada, S.A. Evaluations of some natural antioxidant sources in broiler diets: 1-effect on growth, physiological and immunological performance of broiler chicks. Int. J. Poult. Sci. 2013, 12, 561-571. [CrossRef]

62. Franchini, A.; Canti, M.; Manfreda, G.; Bertuzzi, S.; Asdrubali, G.; Franciosi, C. Vitamin E as adjuvant in emulsified vaccine for chicks. Poult. Sci. 1991, 70, 1709-1715. [CrossRef]

63. Atta, A.H.; Fathy, S.; Gohar, M.; Jan, R.; Kamel, G.; Mouneir, S.M.; Nasr, S.M. Prolonged administration of high doses of copper nicotinate to rats: Effect on biochemical and cellular constituents of blood and on copper level in serum, liver and muscle. Int. J. Med. Med. Sci. 2009, 1, 178-183.

64. Zhang, S.; Noordin, M.; Rahman, S.; Haron, J. Effects of copper overload on hepatic lipid peroxidation and antioxidant defense in rats. Vet. Hum. Toxicol. 2000, 42, 261-264. [PubMed]

65. Letelier, M.E.; Lepe, A.M.; Faúndez, M.; Salazar, J.; Marín, R.; Aracena, P.; Speisky, H. Possible mechanisms underlying copper-induced damage in biological membranes leading to cellular toxicity. Chem. Biol. Interact. 2005, 151, 71-82. [CrossRef] [PubMed]

66. Coles, E. Veterinary clinical Pathology, 4th ed.; WB Saunders Company: London, UK, 1986; pp. 136-170.

67. Abdelazeim, S.A.; Shehata, N.I.; Aly, H.F.; Shams, S.G.E. Amelioration of oxidative stress-mediated apoptosis in copper oxide nanoparticles-induced liver injury in rats by potent antioxidants. Sci. Rep. 2020, 10, 1-14. [CrossRef]

68. Torki, M.; Kaviani, K.; Ghasemi, H. Effects of diet supplementation by copper sulphate and ginger essential oil on growth performance and plasma biochemical parameters of broiler chickens under high environmental temperature conditions. Eur. Poult. Sci. 2014, 78, 62 .

69. Almansour, M.I. Biochemical effects of copper sulfate, after chronic treatment in quail. J. Biol. Sci. 2006, 6, 1077-1082.

70. Prabu, S.M.; Shagirtha, K.; Renugadevi, J. Naringenin in combination with vitamins C and E potentially protects oxidative stress-mediated hepatic injury in cadmium-intoxicated rats. J. Nutr. Sci. Vitaminol. 2011, 57, 177-185. [CrossRef]

71. Idowu, O.; Ajuwon, O.; Fafiolu, A.; Oso, A. Modulation of Cholesterol and Copper Residue Levels in Muscles and Blood Serum of Finishing Broiler Chickens Fed Copper and. Pak. J. Nutr. 2011, 10, 781-785. [CrossRef]

72. Abou-Kassem, D.; Mahrose, K.M.; Alagawany, M. The role of vitamin E or clay in growing Japanese quail fed diets polluted by cadmium at various levels. Animal 2016, 10, 508-519. [CrossRef]

73. Mashkoor, J.; Khan, A.; Khan, M.Z.; Hussain, I. Chromium toxicity and oxidative stress in broiler chicks and its amelioration with vitamin E and bentonite. Int. J. Agric. Biol. 2016, 18, 1103-1108. [CrossRef]

74. Bhattacharyya, S.; Mehta, P. The hepatoprotective potential of Spirulina and vitamin C supplemention in cisplatin toxicity. Food Funct. 2012, 3, 164-169. [CrossRef] [PubMed]

75. Rana, T.; Bera, A.K.; Das, S.; Pan, D.; Bandyopadhyay, S.; Bhattacharya, D.; De, S.; Sikdar, S.; Das, S.K. Effect of ascorbic acid on blood oxidative stress in experimental chronic arsenicosis in rodents. Food Chem. Toxicol. 2010, 48, 1072-1077. [CrossRef]

76. Cinar, M.; Yigit, A.A.; Yalcinkaya, I.; Oruc, E.; Duru, O.; Arslan, M. Cadmium induced changes on growth performance, some biochemical parameters and tissue in broilers: Effects of vitamin C and vitamin E. Asian J. Anim. Vet. Adv. 2011, 6, 923-934. [CrossRef]

77. El-Bahr, S.; Mandour, A.; Hashem, A. Effect of dietary supplementation of selected trace element or ascorbic acid on protein patterns of pre-immunized broiler chickens. Pharm. Pharmacol. Int. J. 2017, 5, 102-110.

78. Imik, H.; Ozkanlar, S.; Kaynar, O.; Koc, M. Effects of vitamin E, C, and $\alpha$-lipoic acid supplementation on the serum glucose, lipid profile, and proteins in quails under heat stress. Bull Vet. Inst. Pulawy 2009, 53, 521-526.

79. Bakalli, R.I.; Pesti, G.M.; RAGLAND, W.L.; KONJUFCA, V. Dietary copper in excess of nutritional requirement reduces plasma and breast muscle cholesterol of chickens. Poult. Sci. 1995, 74, 360-365. [CrossRef]

80. Wu, X.; Zhu, M.; Jiang, Q.; Wang, L. Effects of Copper Sources and Levels on Lipid Profiles, Immune Parameters, Antioxidant Defenses, and Trace Element Residues in Broilers. Biol. Trace Element Res. 2020, 194, 251-258. [CrossRef]

81. Konjufca, V.; Pesti, G.; Bakalli, R. Modulation of cholesterol levels in broiler meat by dietary garlic and copper. Poult. Sci. 1997, 76, 1264-1271. [CrossRef]

82. Paik, I.; Seo, S.; Um, J.; Chang, M.; Lee, B. Effects of supplementary copper-chelate on the performance and cholesterol level in plasma and breast muscle of broiler chickens. Asian Aust. J. Anim. Sci. 1999, 12, 794-798. [CrossRef]

83. Pearce, J.; Jackson, N.; Stevenson, M.H. The effects of dietary intake and of dietary concentration of copper sulphate on the laying domestic fowl: Effects on some aspects of lipid, carbohydrate and amino acid metabolism. Br. Poult. Sci. 1983, 24, 337-348. [CrossRef] [PubMed]

84. Steinberg, D. Low density lipoprotein oxidation and its pathobiological significance. J. Biol. Chem. 1997, 272, 20963-20966. [CrossRef] [PubMed]

85. Burkitt, M.J. A critical overview of the chemistry of copper-dependent low density lipoprotein oxidation: Roles of lipid hydroperoxides, $\alpha$-tocopherol, thiols, and ceruloplasmin. Arch. Biochem. Biophys. 2001, 394, 117-135. [CrossRef] [PubMed]

86. Ganong, W.F. Cardiovascular homeostasis in health and disease. In Review of Medical Physiology, 22nd ed.; McGraw Hill: New York, NY, USA, 2005; pp. 631-646.

87. El-Hady, A.; Mohamed, A. Effect of dietary sources and levels of copper supplementation on growth performance, blood parameters and slaughter traits of broiler chickens. Egypt. Poult. Sci. J. 2019, 39, 897-912. [CrossRef]

88. Niki, E. Interaction of ascorbate and $\alpha$-tocopherol. Ann. N. Y. Acad. Sci. 1987, 498, 186-199. [CrossRef] 
89. Kies, C.; Harms, J.M. Copper absorption as affected by supplemental calcium, magnesium, manganese, selenium and potassium. Adv. Exp. Med. Biol. 1989, 258, 45-58.

90. Van den Berg, G.; Yu, S.; Lemmens, A.; Beynen, A. Dietary ascorbic acid lowers the concentration of soluble copper in the small intestinal lumen of rats. Br. J. Nutr. 1994, 71, 701-707. [CrossRef] [PubMed]

91. Corona-Rivera, A.; Urbina-Cano, P.; Bobadilla-Morales, L.; de Jesús Vargas-Lares, J.; Ramírez-Herrera, M.A.; Mendoza-Magaña M.L.; Troyo-Sanromán, R.; Díaz-Esquivel, P.; Corona-Rivera, J.R. Protective in vivo effect of curcumin on copper genotoxicity evaluated by comet and micronucleus assays. J. Appl. Genet. 2007, 48, 389-396. [CrossRef] [PubMed]

92. Zhong, Y.; Feng, S.; Luo, Y.; Zhang, G.; Kong, Z. Evaluating the genotoxicity of surface water of Yangzhong city using the Vicia faba micronucleus test and the comet assay. Bullet. Environ. Contam. Toxicol. 2001, 67, 217-224. [CrossRef] [PubMed]

93. Andrighetti-Fröhner, C.R.; Kratz, J.M.; Antonio, R.V.; Creczynski-Pasa, T.B.; Barardi, C.R.; Simões, C.M. In vitro testing for genotoxicity of violacein assessed by Comet and Micronucleus assays. Mutat. Res. Genet. Toxicol. Environ. Mut. 2006, 603, 97-103. [CrossRef] [PubMed]

94. Urbina-Cano, P.; Bobadilla-Morales, L.; Ramírez-Herrera, M.A.; Corona-Rivera, J.R.; Mendoza-Magaña, M.L.; Troyo-Sanromán, R.; Corona-Rivera, A. DNA damage in mouse lymphocytes exposed to curcumin and copper. J. Appl. Genet. 2006, 47, 377-382. [CrossRef]

95. Banu, B.S.; Ishaq, M.; Danadevi, K.; Padmavathi, P.; Ahuja, Y. DNA damage in leukocytes of mice treated with copper sulfate. Food Chem. Toxicol. 2004, 42, 1931-1936. [CrossRef]

96. Nair, J.; Strand, S.; Frank, N.; Knauft, J.; Wesch, H.; Galle, P.R.; Bartsch, H. Apoptosis and age-dependant induction of nuclear and mitochondrial etheno-DNA adducts in Long-Evans Cinnamon (LEC) rats: Enhanced DNA damage by dietary curcumin upon copper accumulation. Carcinogenesis 2005, 26, 1307-1315. [CrossRef]

97. Hayashi, M.; Kuge, T.; Endoh, D.; Nakayama, K.; Arikawa, J.; Takazawa, A.; Okui, T. Hepatic copper accumulation induces DNA strand breaks in the liver cells of Long-Evans Cinnamon strain rats. Biochem. Biophys. Res. Commun. 2000, 276, 174-178. [CrossRef]

98. Bjelland, S.; Seeberg, E. Mutagenicity, toxicity and repair of DNA base damage induced by oxidation. Mutation Res. Fund. Mol. Mech. Mutag. 2003, 531, 37-80. [CrossRef]

99. Tchounwou, P.B.; Newsome, C.; Williams, J.; Glass, K. Copper-induced cytotoxicity and transcriptional activation of stress genes in human liver carcinoma (HepG2) cells. In Proceedings of the International Symposium on Metal Ions in Biology and Medicine, Corsica, France, 18-23 May 2008; p. 285.

100. Traber, M.G.; Stevens, J.F. Vitamins C and E: Beneficial effects from a mechanistic perspective. Free Rad. Biol. Med. 2011, 51, 1000-1013. [CrossRef]

101. Jiraungkoorskul, W.; Sahaphong, S. Efficacy of ascorbic acid reducing waterborne copper toxicity in butterfish (Poronottus triacanthus). J. Biol. Sci. 2007, 7, 620-625. [CrossRef]

102. Assy, W.; Wasef, M.; Abass, M.; Elnegris, H. A Study of Short Term Chronic Pulmonary Toxicity, Neurotoxicity and Genotoxicity of Copper Oxide Nanoparticles and The Potential Protective Role of Vitamin E on Adult Male Albino Rats. Zagazig J. Forensic Med. 2019, 17, 1-18. [CrossRef]

103. Zwolak, I. Protective effects of dietary antioxidants against vanadium-induced toxicity: A review. Oxid. Med. Cell. Longev. 2020, 2020, 1490316. [CrossRef] [PubMed]

104. Baruah, S.; Goswami, S.; Kalita, D. Haematobiochemical and Pathological Alterations of Chronic Copper Toxicity in Ducks. J. Anim. Res. 2018, 8, 283-287.

105. Liu, J.; Zhao, H.; Wang, Y.; Shao, Y.; Li, J.; Xing, M. Alterations of antioxidant indexes and inflammatory cytokine expression aggravated hepatocellular apoptosis through mitochondrial and death receptor-dependent pathways in Gallus gallus exposed to arsenic and copper. Environ. Sci. Pollut. Res. 2018, 25, 15462-15473. [CrossRef] [PubMed]

106. Jackson, N.; Stevenson, M.H.; Kirkpatrick, G.M. Effects of the protracted feeding of copper sulphate-supplemented diets to laying, domestic fowl on egg production and on specific tissues, with special reference to mineral content. Br. J. Nutr. 1979, 42, 253-266. [CrossRef] [PubMed]

107. Khatun, M.F.; Hasan, M.M.; Islam, R.; Sarkar, S.; Haque, M.A. Effect of spirulina (Spirulina platensis) and vitamin E on arsenic induced toxicity in Quail. Asian J. Med. Biol. Res. 2020, 6, 93-98. [CrossRef] 